\title{
When You Eat Matters: 60 Years of Franz Halberg's Nutrition Chronomics
}

\author{
Germaine Cornelissen*
}

Halberg Chronobiology Center, University of Minnesota, Minneapolis, MN, USA

\begin{abstract}
Franz Halberg revolutionalized the field of nutrition by his demonstration that "when" we eat can make the difference between life and death in the experimental laboratory, and between weight gain or weight loss in everyday life. His critical contributions have far-reaching implications, whether for feeding the under-nourished in populations stricken by starvation, or for managing one of today's great scourges in the more opulent countries, namely obesity. The use of a calorie consumed in the morning differs from that of one ingested in the evening, contributing, as he also showed, to different hormonal relations prevailing when a single daily meal is taken as breakfast-only or dinner-only. Important mechanisms underlying metabolism as they relate to health and longevity uncovered by Franz in the innumerable studies he designed and conducted on several continents remain beyond the frontier of current scientific investigations, attesting to his visionary leadership, his ability to look at the facts without any preconceived ideas, and his truly amazing humility and eagerness to serve.
\end{abstract}

Keywords: Chronobiology, circadian, meal timing, food restriction, starvation, synchronizer, lifespan, cancer, blood pressure, weight, suprachiasmatic nuclei.

Dedicated to Franz Halberg, a mentor and a father, on the occasion of his $92^{\text {nd }}$ birthday.

\section{HISTORICAL CONTEXT}

Already by $5000 \mathrm{BC}$, it was known that we are what we eat [1]. The familiar aphorism "Dis-moi ce que tu manges, je te dirai qui tu es" ("Tell me what you eat, I will tell you who you are") or its popular paraphrase "You are what you eat" is number four in a list at the beginning of volume 1 of Brillat-Savarin's Physiologie du Goût [2]. But Brillat-Savarin's third aphorism bears attention as well: "La destinée des nations dépend de la manière dont elles se nourissent" ("The destiny of nations depends on how they are nourished"). In other words, "You are how you eat". According to Franz Halberg's interpretation, this should first and foremost include "You are when you eat" [cf. 3] ${ }^{1}$.

\section{FAILURE OF THE EPINEPHRINE TEST, FOOD RESTRICTION STUDIES, AND THE BIRTH OF CHRONOBIOLOGY}

Chronobiology came about from Franz Halberg's studies on blood eosinophil cells as a gauge of adrenocortical function. At Harvard, he was the only one in his setting who

*Address correspondence to this author at the 420 Delaware Street SE (MMC 8609), Minneapolis, MN 55455; Tel: 612-624-6976;

Fax: 612-624-9989; E-mail: corne001@umn.edu

Web. www.msi.umn.edu/ halberg/

\footnotetext{
${ }^{1}$ Virey also had thoughts about a "different temperament" as a function of whether one eats a single daily meal in the morning or in the evening [3]. A single numerical summary pertains to chronobiology, but not to nutrition. It is a table of overall mortality statistics recorded monthly at the Val-de-Grace military hospital as a function of clock hour for 13 months. From these limited data allowing detection by cosinor of neither a circadian nor a circannual component, Virey extrapolated that "the prudent physician has to consider any aggravating circumstances for each disease (which is not indicated in his table).
}

debunked the basis of a then-widely-used epinephrine test ${ }^{2}$ published for clinical use in an era before direct hormonal assays were developed [4]. Theoretically, epinephrine was believed to stimulate the hypothalamus, which secreted a substance stimulating pituitary ACTH secretion, which in turn resulted in corticosteroid secretion. An epinephrine

${ }^{2}$ Franz Halberg had, and continues to have a series of disagreements with opinions prevailing in textbooks and with concepts currently generally used, such as homeostasis, i.e., the constancy of the internal environment. The current, nearly exclusive reliance on vital signs and on laboratory values above or below a target (as in the case of blood pressure) or outside versus inside a normal range (as for endocrine determinations), justifies the current reliance of most if not all medicine on singlesample spotchecks, asking whether a given value is too high or too low and discussing up- or down-regulation, while ignoring rhythm characteristics such as the period, amplitude and phase that can also be altered, sometimes in the absence of a change in the mean value. In the case of blood pressure and heart rate, alterations of their variability patterns are invaluable harbingers of cardiovascular disease risk. Starting with the eosinophil count-based epinephrine test, and thereafter for cell division and eventually for nucleic acid formation and for the effect of radiation and of numerous drugs, it became repeatedly apparent to Franz in empirical terms that the superficially useful generalization of relative constancy by the older Claude Bernard, which led to the "hunting" of Walter Bradford Cannon's homeostasis, is a wasteful fundamental error, as is ignoring rhythms as a first approximation, or the occasional comparison of rhythmic and (imaginary) homeostatic mechanisms. By 1949-50 in Minnesota, Franz realized that he could do better by using variability as an asset rather than trying to eliminate it, as he had at first done at Harvard in 1948-49. There, for assaying cortisone-like activity in the mouse, he needed $2.8 \mathrm{mg}$ of cortisone to eliminate the 24 hour rhythm for 24 hours [186]. Soon thereafter, he could increase the sensitivity to cortisone to a very few $\mu \mathrm{gs}$ (not mgs) by working in the physiologic range, carrying the tests in the ascending stage of the about-daily rhythm (that he had called circadian), once the variability in eosinophil counts became clear to him [187]. At his farewell from Harvard in 1949, Franz's department head, George W Thorn, the late Hersey Professor of the Theory and Practice of Physics, told him that he admired Halberg's sticking to his guns (to his unpublished work in Boston about an eosinophil count decrease in adrenalectomized mice), yet it could not be that Halberg was right while "everyone else" (including perhaps a dozen or more distinguished senior colleagues in the same department and some others elsewhere) was wrong. Halberg's results in the mouse were soon amply extended to humans by William R Best [7] and the epinephrine test went into oblivion. The dictum prevailing with some outspoken colleagues at the Peter Bent Brigham hospital, if not also at Harvard, was to "publish, and if you are right, you are a success, but if you are wrong, everybody will forget it". The dozen or so colleagues were wrong, but, of course, today, everybody forgot it, as the late Thorn did himself, without so much as an apology on subsequent returns by Franz to Harvard for lectures or an NIH study section. 
injection was anticipated to fail to depress the count of eosinophils (circulating white blood cells staining with the acid dye eosin) if the adrenal cortex was absent or deficient [5]. Although the test had worked for a number of his colleagues at Harvard, it failed in Halberg's adrenalectomized mice, since epinephrine considerably depressed the blood eosinophil count even after removal of the adrenal glands and adrenal cortex-like (ectopic) tissue elsewhere in the body. By the time the epinephrine test was reconsidered and eliminated within a year [6-8], Franz had joined the University of Minnesota. There, on separate but comparable groups of inbred mice of different strains, he documented the circadian rhythm in blood eosinophils, dropping from high counts in the morning to low counts in the evening, the circadian variation depending upon their genetic make-up $[9,10]$.

The importance of the feeding schedule on the circadian rhythm of eosinophil counts came to the fore by trying to answer the question whether an adrenocortical activation could be used to treat breast cancer and prolong life. As seen in Fig. (1), eosinophil counts were indeed lowered by fasting (or "stress"), achieved by a 50\% reduction in dietary carbohydrates and fats in $\mathrm{C}_{3} \mathrm{H}$ mice with a high incidence of breast cancer. But larger groups of animals were needed to verify whether steroids that depress eosinophil cell counts and perhaps mitoses could be a mechanism through which caloric restriction and ovariectomy act in reducing cancer incidence. Handling larger numbers of animals required starting the experiment at an earlier clock hour. Halberg had the foresight of interpreting the resulting lack of a difference (Fig. 2) as stemming from a phase difference between the caloric-restricted and the fully-fed groups. His postulate was confirmed when another experiment starting even earlier on larger groups of animals yielded opposite results, Fig. (3). $\mathrm{He}$ had thus illustrated the dangers of ignoring a phase

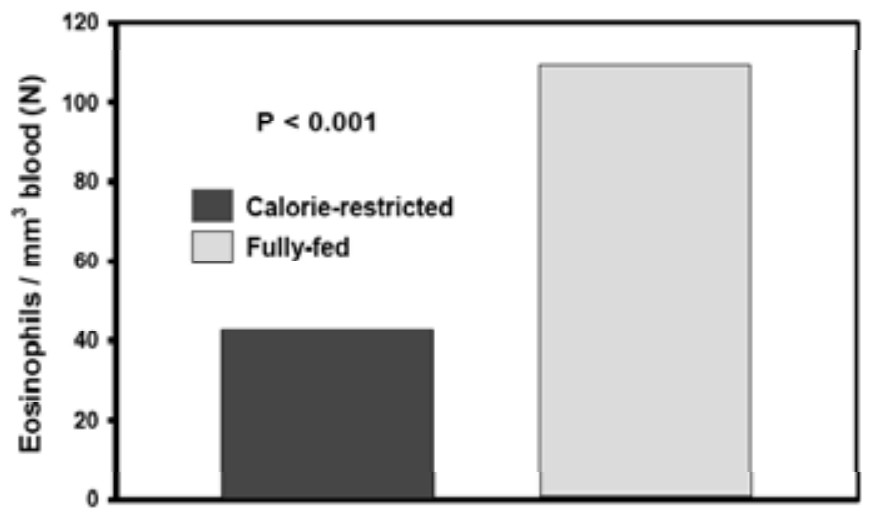

Fig. (1). Eosinophil counts lowered by "fasting" and/or "stress". Effect of a 50\% reduction in dietary carbohydrates and fats (with proteins, vitamins and minerals as in control group) in $\mathrm{C}_{3} \mathrm{H}$ mice with a high breast cancer incidence, which is greatly lowered by a diet reduced in calories. Is an adrenocortical activation, then assessed by eosinophil depression, an answer for treating breast cancer and for prolonging life? This exciting finding of a difference in eosinophil count between two groups of mice had to be replicated on a larger group of animals because of its importance to the etiology of cancer. Steroids that depress eosinophil cell counts and perhaps mitoses could be a mechanism through which caloric restriction and ovariectomy act in greatly reducing cancer incidence. (C) Halberg (with permission).

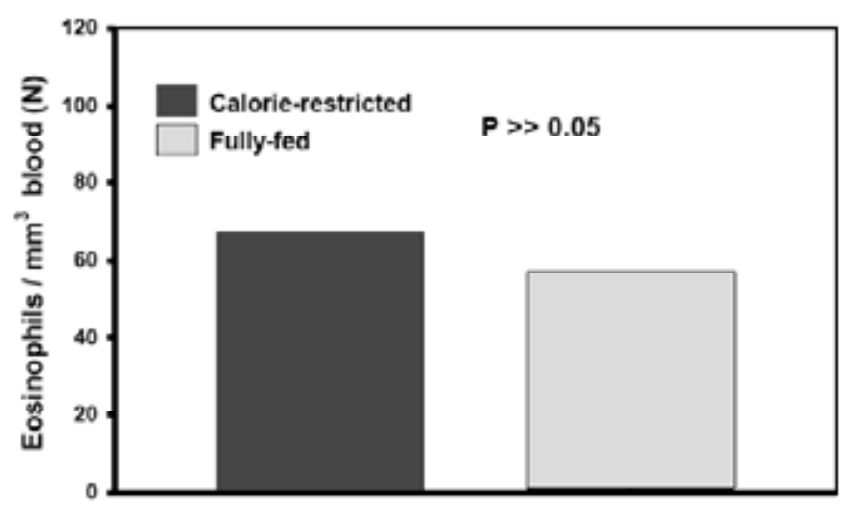

Fig. (2). The large inter-group difference in eosinophil count was not replicated when more animals were used with an earlier start. Confusing results were obtained a week after Figure 1's study in a follow-up investigation using more animals. Sampling started at an earlier clock hour. Instead of the large anticipated difference, results indicated "no difference". A phase difference between the two groups could account for the discrepancy. (C) Halberg (with permission).

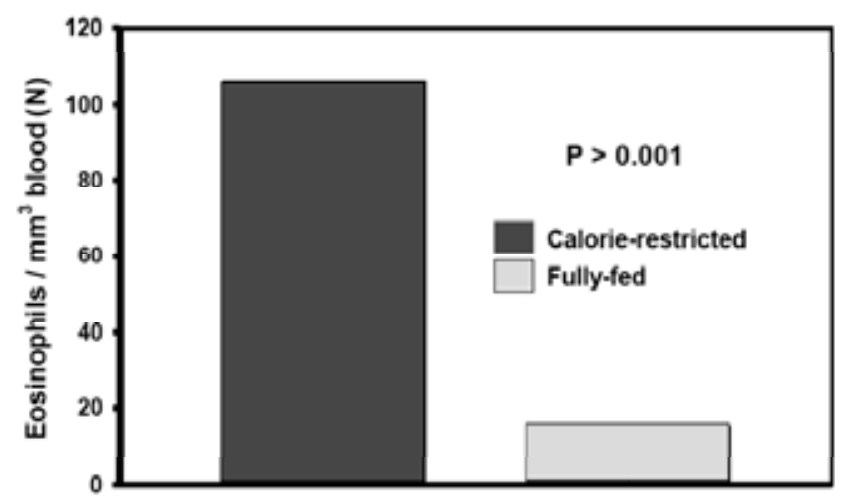

Fig. (3). Results from another follow-up with even more animals, sampling starting at an even earlier clock hour. Opposite outcome led to the question whether "stress" had become "allergy". Erroneous conclusions derived from ignoring a phase difference in circadian rhythm due to competing synchronization. (C) Halberg (with permission).

difference in the circadian rhythm of the two groups being compared due to the competing synchronization of the lighting and feeding schedules [11].

These experiments also revealed that food restriction in mice lowers circulating eosinophil counts and amplifies their circadian rhythm [12], as illustrated in Fig. (4). When both the phase and the amplitude of the circadian rhythm are changed by a given intervention, these changes possibly overshadowing any difference in mean value, there is no choice but to assess the rhythm by around-the-clock sampling, complemented by the derivation of point and interval estimates of rhythm parameters. Failure to do so is bound to mislead. Rhythms (circadians and many other periodic changes) are the indispensable control.

\section{LIFE OR DEATH STUDIES AND THE CRITICAL IMPORTANCE OF CHRONOBIOLOGY}

Extensive studies by Halberg with collaborators worldwide accumulated a body of evidence documenting the 


\section{EFFECT OF FOOD RESTRICTION ON CIRCULATING EOSINOPHILS IN MICE}

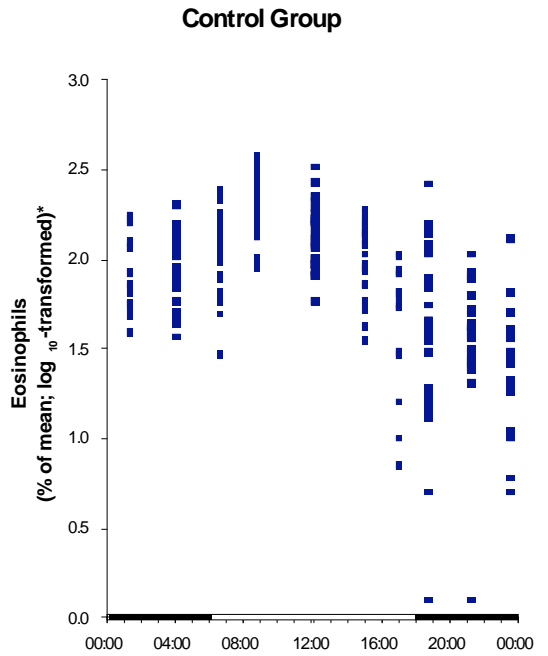

Underfed Group

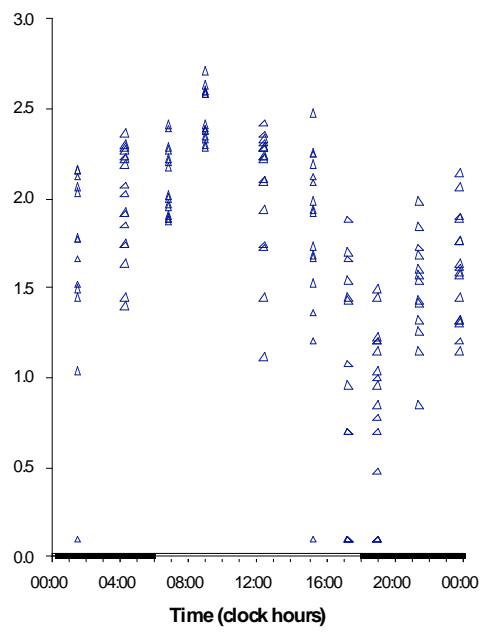

Superposed Groups ${ }^{*}$

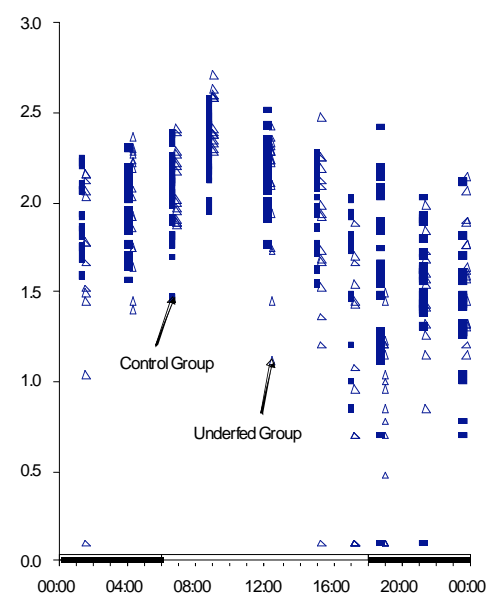

* After log10 -transformation of data expressed as percentage of mean.

** To reveal the difficulty to resolve differences by the naked eye alone, and the even greater difficulty of qua of each group and any inter -group differences.

ntifying the patterns

\section{FOOD RESTRICTION AMPLIFIES CIRCADIAN RHYTHM OF CIRCULATING EOSINOPHILS IN MICE*}

Control Group

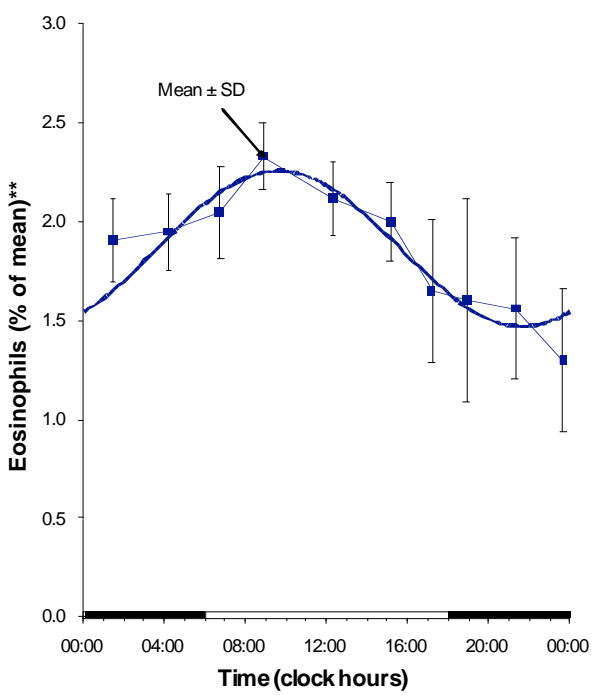

Underfed Group

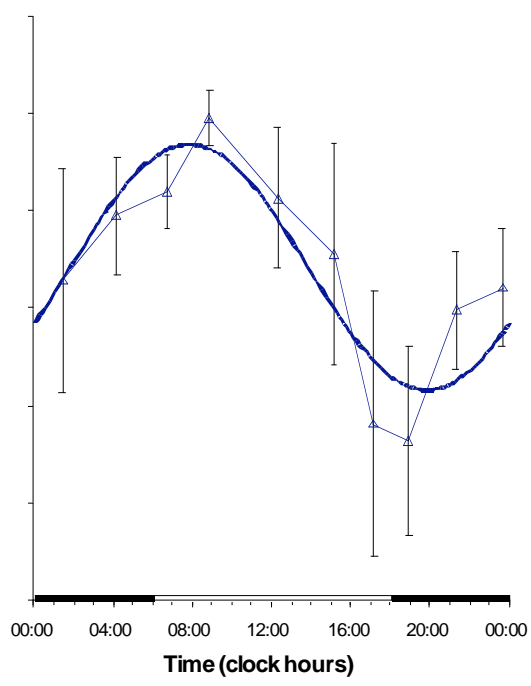

* $\mathrm{P}<0.001$ from test of equality of amplitudes

${ }^{* *}$ After $\log _{10}$-transformation of data expressed as percentage of mean.

(B)

Fig. (4). (A). There is a need to cover the 24-hour time scale to look for intergroup differences in the face of a large variability. An analysis of variance shows statistically significant time and group effects and interaction. (C) Halberg (with permission). (B). Parameter estimations and comparisons can be derived by the fit of a 24-hour cosine curve (shown with original timepoint means \pm 1 standard error). Circulating eosinophil counts of the underfed group are lower $(\mathrm{P}<0.001)$ than those of the control group. The circadian pattern of the underfed group has a larger amplitude $(\mathrm{P}<0.001)$ and an earlier acrophase $(\mathrm{P}=0.003)$ as compared to that of the control group. (C) Halberg (with permission). 


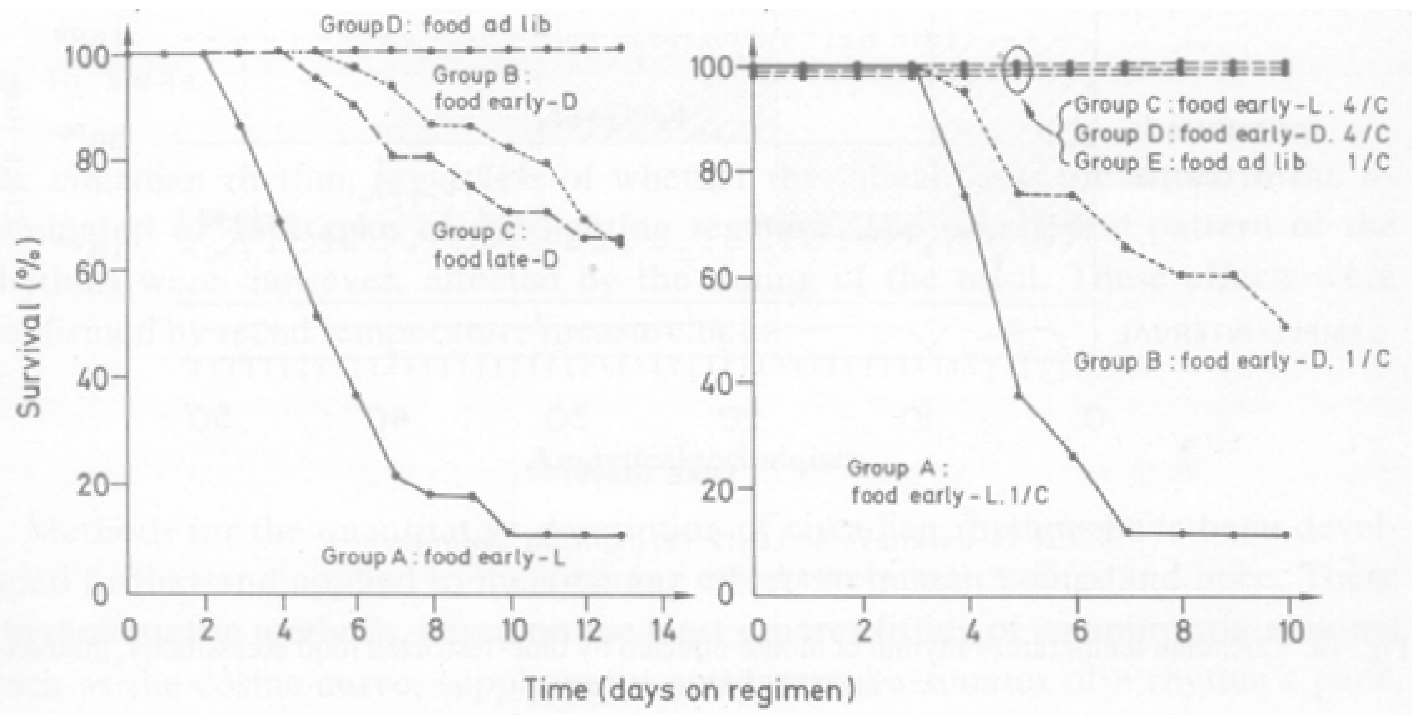

Fig. (5). Left: Survival of singly-housed mice is determined by timing of single daily meal. Right: Survival of mice depends on housing conditions and on timing of single daily meal. (C) Halberg (with permission).

ubiquity and critical importance of circadian (and other) rhythms. Not only were most variables in most organisms circadian rhythmic, the response of these organisms to a given intervention also changed predictably in a circadianrhythmic fashion, whether it was noise, X-irradiation, a variety of drugs, or surgery [13-17]. It came as no surprise then that the response to a single daily "meal" made the difference between life and death in a mammalian model of potentially fatal interactions between hunger, cold and rhythms, namely the singly-housed mouse abruptly restricted to a single daily "meal"3. The short-term survival of the

${ }^{3} \mathrm{~A}$ plan for a study of the difference between life and death to explore the importance of timing food consumption under conditions of a restricted availability of calories originated on one of Franz's many visits to India with his wife Erna and, in alternation, with one or the other of his two daughters. On one of these trips, Erna, Franz and their younger daughter Julia flew first to Shimla, where they were guests of the governor of Himachal Pradesh. The weather was cold in the Himalayas that winter. They came for dinner unannounced and encountered their hosts and other guests gathered around a fire, slightly shivering. From Shimla, they flew to Varanasi (Banaras), where they were greeted by palm trees. They were housed in a former British governor's brick mansion. It was cool but not cold. A newspaper arrived with the morning tea, reporting many deaths, perhaps related to a combination of poor clothing, little food and only cool (not cold) weather. It was tempting to see whether the equivalent could be reproduced objectively in the laboratory, in mice with little fat reserves, prevented from cuddling by single housing, kept in cool but not cold temperatures. Indeed, the difference between life and death, depending on when the same amount of food was made available, could be objectively demonstrated (see Fig. 5) [110]. Franz had also checked and found a different use of calories at breakfast-only versus dinner-only, in the light of the particular hormonal environment that he eventually found to differ on these two dietary schedules. When he reported his results on the different metabolic use of a calorie by timing in relation to the internal environment, his friend Vulimiri Ramalingaswami, who headed the All-India Institute for Medical Research in New Delhi, smiled and indicated that he confronted as the major problem the loss to rats of about $20 \%$ of each grain shipment from the USA. The rodents were thus the first unintended beneficiaries of President Eisenhower's Food for Peace (PL-480) program. Friends in high places notwithstanding, to Franz's knowledge, timing the ingestion of food was never tested under conditions of famine. The number of projects Franz started in India included a Golden Fleece Award (for waste of taxpayer money by federal government agencies, created by William Proxmire, then the Democratic senator from Wisconsin) for a misunderstanding of Franz's project on about-yearly rhythms in the Jamuna River catfish, described as a study of the "love life" of that organism since ovary size was an endpoint. The major result of Franz's many projects in India, however, sadly unutilized as yet, is the doubling of the 2-year disease-free survival rate of patients with oral cancers by personalized timing of radiotherapy according to tumor temperature used as a marker rhythm, a project implemented by Dr Akhil Deka, guided by Dr BD Gupta, the then young and always enthusiastic head of radiotherapy at the Postgraduate Institute for Medical Education and Research in Chandigarh. On that trip, Franz, Erna and their older daughter Francine, now a clinical radiotherapist, introduced rhythmometry by around-the-clock oral tumor temperature measurements. Turning mouse depends on the timing of the "meal" in relation to a regimen of light and darkness alternating at 12-hour intervals. Most animals survive when they have access to food for 4 hours during the first part of the dark (active) span each day, but if food is only available during 4 hours in the early part of the light (rest) span, most of the mice die [18, 19], Fig. (5). Body heat loss plays a critical role since housing the mice in groups or raising the room temperature prevents deaths on these regimens [18], Fig. (5) (right).

In humans as well, Halberg found that the timing of a single daily meal makes the difference between weight loss and weight gain. Whether fixed to 2000 calories or freechoice, single daily meals consumed as breakfast-only versus dinner-only were associated with a relative weight loss at breakfast [20, 21], Fig. (6). These studies clearly showed that the use of a calorie consumed at one time of day is different from that of the same calorie consumed at another time of day, and that the internal time relations among ubiquitous rhythms characterizing the entire metabolic, notably endocrine, system contribute to this difference, Figs. (7 and 8). These figures visualize that the timing of cortisol moved least by the change from a single daily meal as breakfast versus dinner, by contrast to other hormones. Thus, timing a meal greatly alters the internal endocrine and thus the metabolic milieu. Evidence presented in the following sections illustrates the critical importance of rhythms in understanding how food intake relates to longevity and health. This knowledge could serve as a founding block for fighting today's major civilization diseases.

from nutrition and cancer to cardiology, the interest in the prevention of cardiovascular disease of Professor RB Singh, the editor-in-chief of this journal and Franz's newest and most welcome Indian friend, is leading to new collaborative work, notably on the screening for newly discovered Vascular Variability Disorders (VVDs) and on the circadian susceptibility-resistance rhythms to a number of drugs and other agents. The higher vulnerability of the human heart in the morning hours [188] prompted Dr RB Singh to point out in a recent discussion with a small circle of friends in the author's home that a big morning meal may enhance the risk of a heart attack in people at a high risk of coronary heart disease. This circumstance cannot necessarily be extended to healthy people who indeed, as folklore has long recognized, may preferably eat like a king in the morning and like a pauper in the evening. 


\section{Relative Body Weight Loss on a Single Meal (2000 calories) at Breakfast}
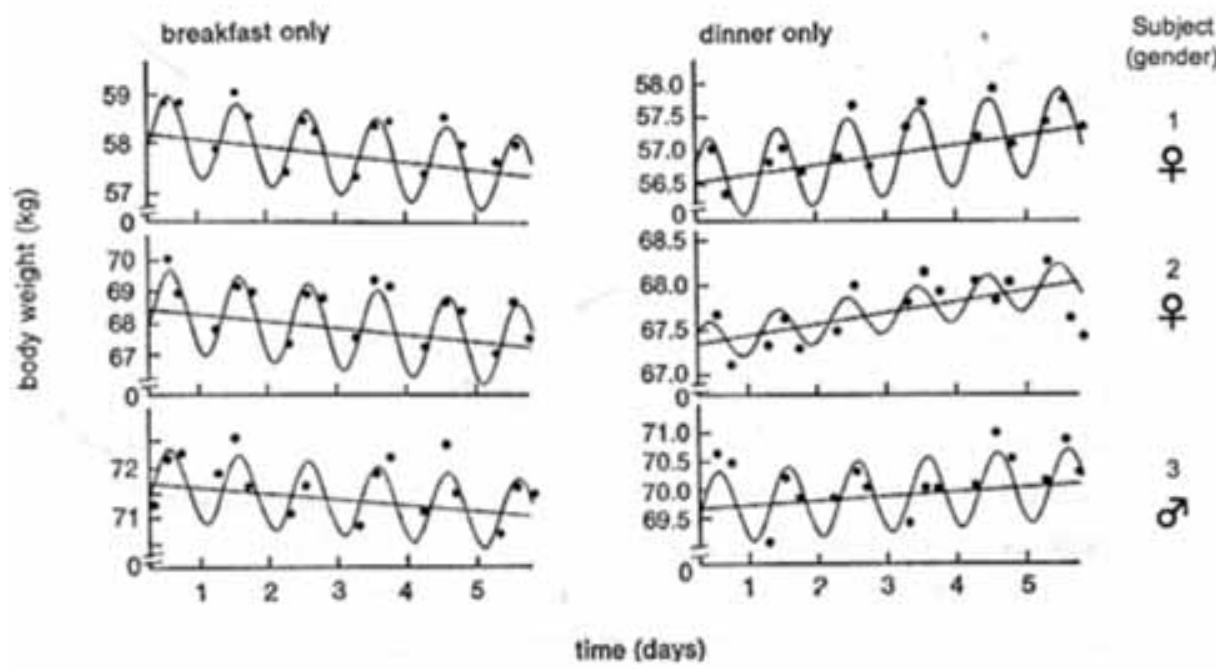

Fig. (6). Change in body weight as a function of time for 3 subjects while they ate a single daily meal either as breakfast (left) or dinner (right). Whereas similar 2000 calories were consumed in each meal, body weight decreased on breakfast only, while it increased on dinner only. (C) Halberg (with permission).

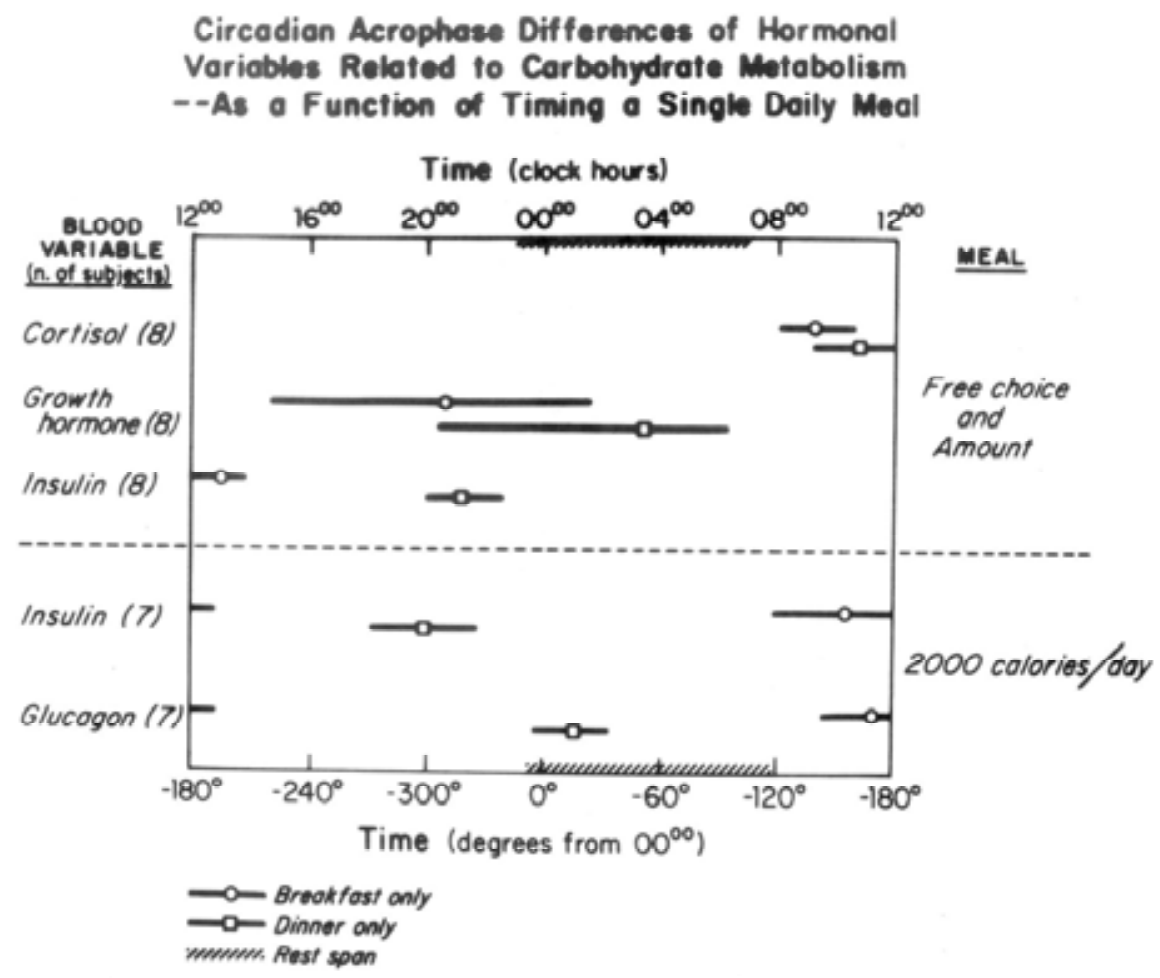

Fig. (7). Circadian acrophase map of hormonal variables related to carbohydrate metabolism. Acrophases differ as a function of the timing of a single daily meal. (C) Halberg (with permission).

\section{PERSISTENCE OF CIRCADIAN RHYTHMS DURING STARVATION}

To demonstrate that circadian rhythms are more than a mere response to environmental synchronizers, it is customary to show their persistence under constant conditions. Usually, only light intensity, temperature and humidity are kept constant. The fact that they can be detected even during starvation is one more piece of evidence attesting to their critical importance.

A periodicity in mammalian liver glycogen was discovered in histologic sections by Forsgren [22, 23]. The 


\section{Differential Displacement ${ }^{*}$ of Circadian Hormonal Timing as a Result of Changing a Single Daily Meal from Breakfast to Dinner}

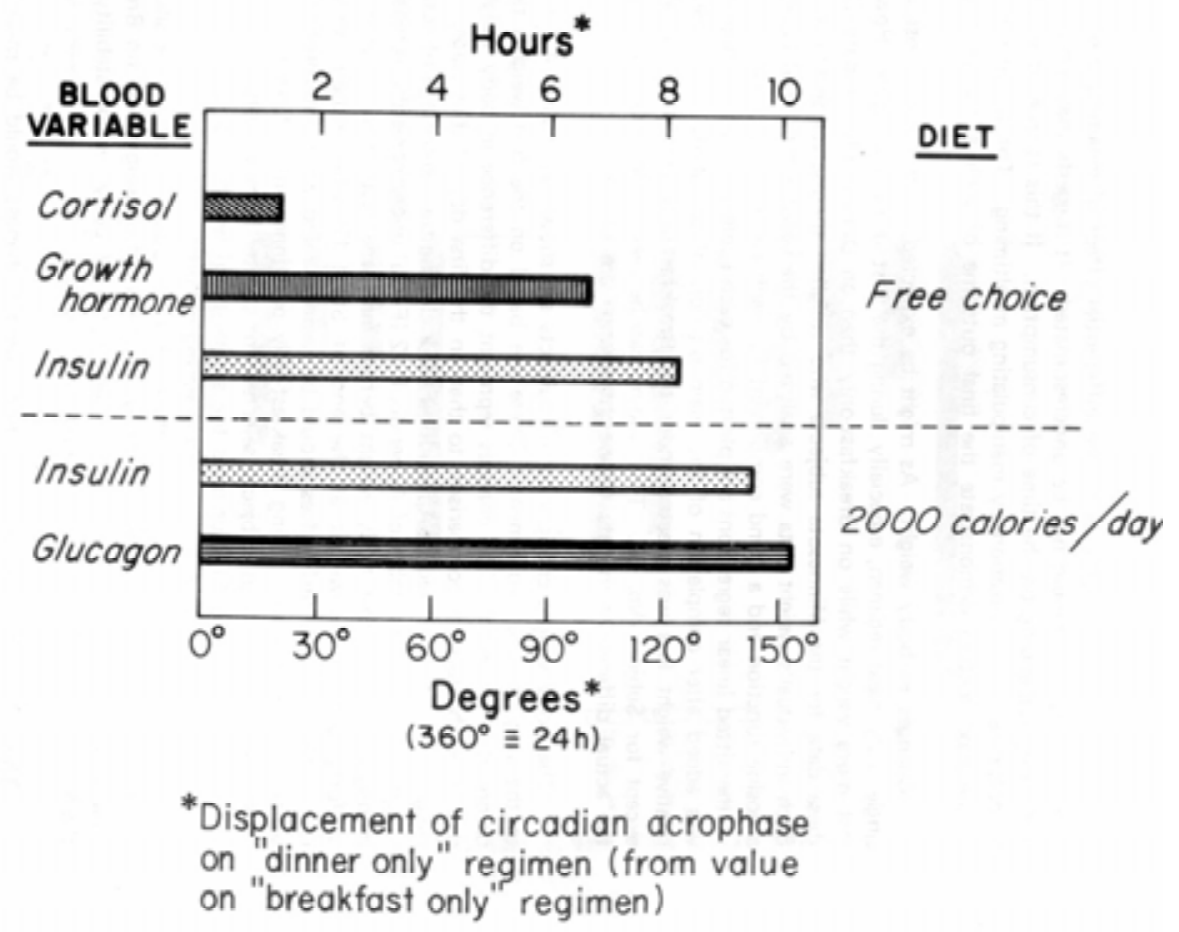

Fig. (8). A large difference in the timing of the circadian insulin rhythm is seen on breakfast-only vs. dinner-only, whether the diet involves items of some limited choice or a fixed diet of 2,000 calories/day. In the same human circulation, there is a much lesser difference in the timing of the circadian rhythm of cortisol. (C) Halberg (with permission).

large circadian changes in glycogen content of rodent liver were chemically confirmed a few years later by Ågren et al. [24]. In their publication, a figure reveals that circadian changes persisted in animals deprived of all food, leading the authors to conclude that the changes could not be "feeding phenomena". Little, if any, alteration occurs in the dynamic rhythm characteristics, as compared to usual ad lib conditions, once the data are expressed as a percentage of the overall series mean $[24,25]$. The circadian rhythm in liver glycogen also persists in data from Ågren [26] on adrenalectomized rats, documented by Sollberger [27], who comments on the surprising similarity of the rhythms in liver glycogen of starved and adrenalectomized rats.

The demonstration by ̊̊gren et al., [24] extended to a mammalian glycogen depot an avian finding by Chossat who reported in 1843 a day-night difference in the cloacal temperature of pigeons [28]. The difference persisted in the absence of food and water for well over a week, until death from starvation and dehydration, Fig. (9). Starvation was apparently associated with an increase rather than a decrease in variability, Fig. (9).

Liver glycogen in the presence and absence of food was further studied in 1933 by Mayo scientists who confirmed the circadian rhythm in intact animals [29]. The glycogen content being much lower in the starving than in the freelyfeeding rodents, the authors concluded that the circadian variation stemmed from a feeding phenomenon rather than being built-in ${ }^{4}$. But once the data are expressed as a percentage of the mean, the relative changes in starving animals became comparable to those of the fed animals, as reported by Haus and Halberg [30, 31]. This finding was dramatic under standardized conditions 5 . Figs. (10 and 11) illustrate the persistence of the liver glycogen rhythm during deprivation of food and water. The results suggest the continuation of a cycle in energy stores, presumably in response to fluctuating endogenous as well as exogenous needs [32].

A within-day variation in caloric requirements is not completely accounted for by the 24-hour rest-activity cycle, as demonstrated in a series of experiments by Halberg as well as by others. Circadian rhythms in basal metabolism have been described for man [33-35] as well as for laboratory animals [36]. A study on rats [37] indicates that

\footnotetext{
${ }^{4}$ Around 1950 , simply by removing the food tray each night (at the start of the daily dark span) and replacing a diet restricted in calories each morning (at the start of the daily light span in the animal room), and waiting for the effect, Franz learned that eventually the timing of the daily rhythm in counts of blood eosinophil cells could be reversed: instead of the daily high count at noon and low count at night, the count was higher by night than by day. Only many decades later did the community of scholars realize this fact and utilized it by manipulating the timing of a diet restricted in calories.

${ }^{5}$ The prestige of the Mayo scientists was so great, and the glycogen content during starvation was so low when expressed as such, that any rhythmicity was disregarded when Franz entered the field. With his standardization of conditions of observation, and in particular after his transformation of displays into a percentage of the mean, the extreme variability of the younger Claude Bernard could be undeniably demonstrated, even in the absence of food intake (see Fig. 11).
} 


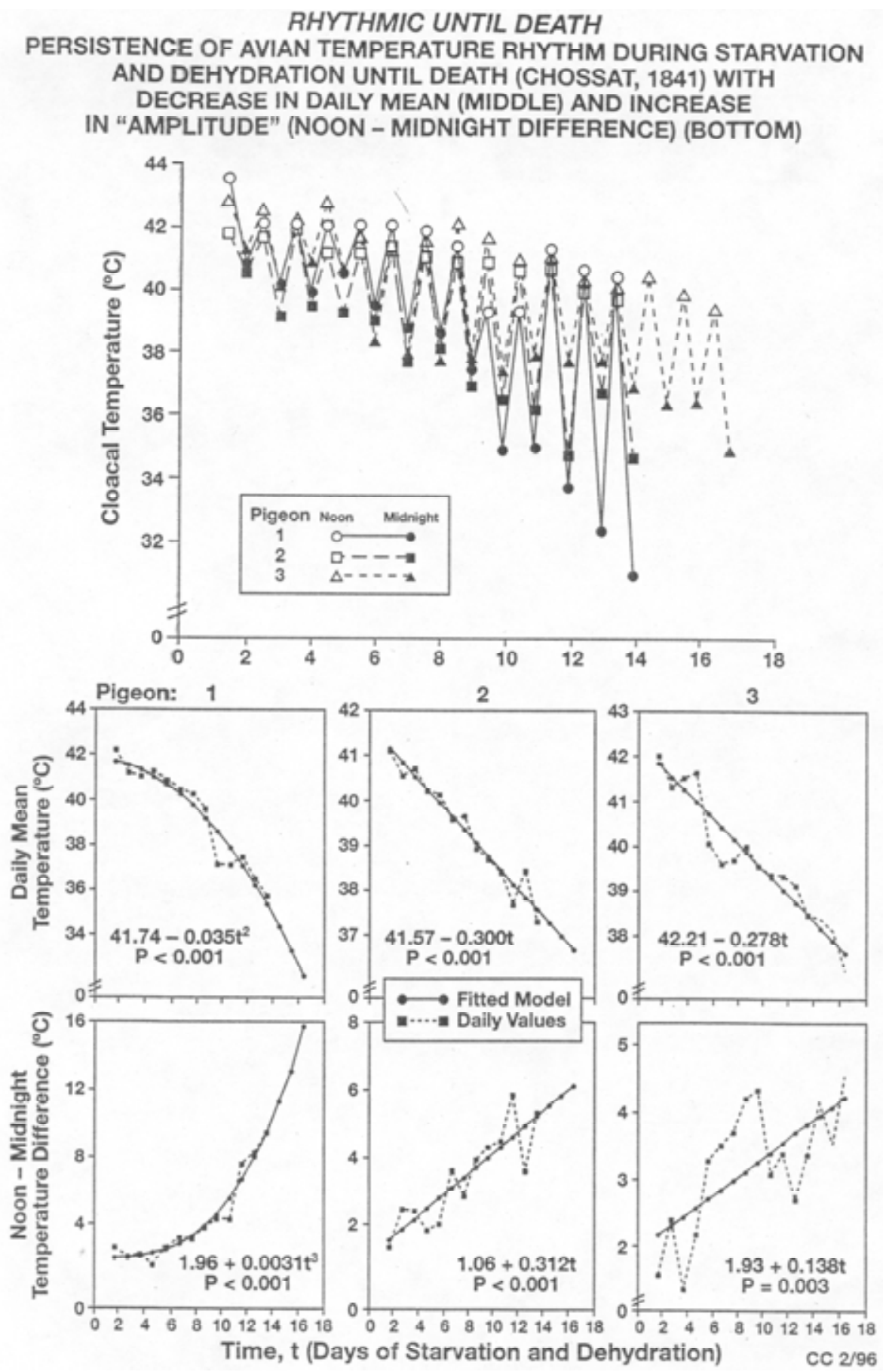

Fig. (9). Demonstration by Charles Chossat (1843) that the circadian rhythm (gauged by measurements at noon and midnight) of cloacal temperature of pigeons deprived of all food and water persists until the day of death from starvation and dehydration. Top: Records from 3 pigeons. Bottom: Changes in daily averages (row 1) and noon-midnight differences (row 2) as a function of time. Second-order polynomials fitted to these data indicate that while the average temperature decreases the prominence of the circadian variation increases. $(0)$ Halberg (with permission).

hunger is not solely a function of the time elapsed since the last meal but varies according to a circadian rhythm. The circadian rhythm in susceptibility of mice to ethanol also persisted after deprivation of either food or water for up to 48 hours [38]. Circadian rhythms in pituitary adrenocorticotropic activity, pinnal mitosis and rectal temperature, as well as in the corticosterone content of serum and adrenal persisted in inbred Bagg albino (C) mice deprived of food and water [39]. Persistence of the circadian cycle in blood eosinophil counts in $\mathrm{C}$ mice kept without food and water for 36 hours was demonstrated as early as 1963 [40].

Circadian rhythms in human subjects have also been shown to persist when isocaloric meals are presented at equal intervals along the 24-hour scale. A circadian rhythm in circulating cortisol was documented with statistical significance in 3-hourly blood samples for 24 hours in three 


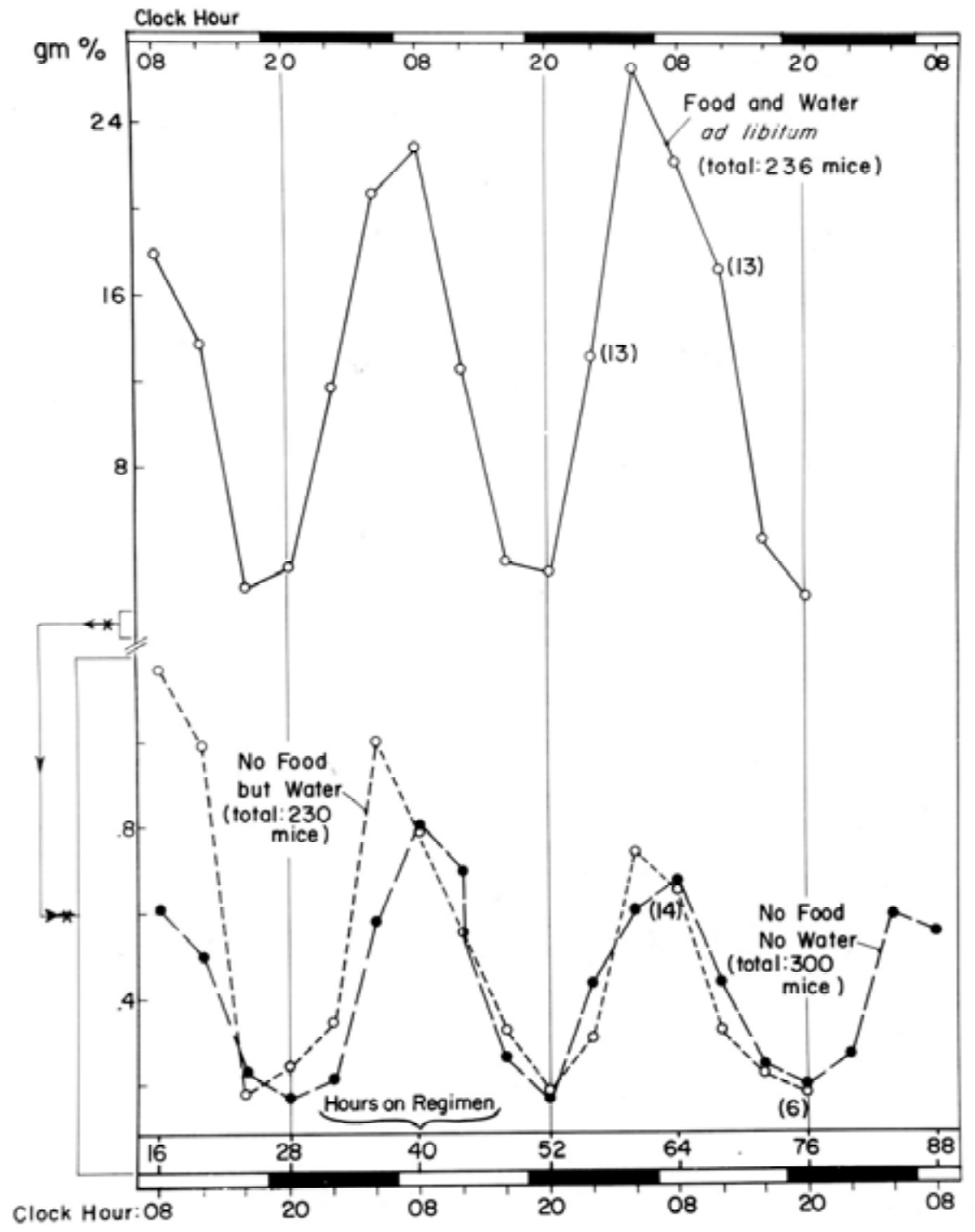

Fig. 12. Liver glycogen concentration in $\mathrm{C} q$-mice, $\sim 4.5$ months of age.*

- 15 mice per point, unless otherwise noted in ( ).

Fig. (10). Liver glycogen concentration in female $\mathrm{C}$ mice at about 4.5 months of age (15 mice per timepoint; otherwise noted in parentheses). (C) Halberg (with permission).

groups of 6-7 apparently healthy subjects, fed 3 meals a day (at 07:00, 12:45 and 16:45), fed isocaloric portions every 3 hours, or fasting. The overall variability accounted for by the circadian rhythm compared favorably in the starving and equidistantly isocalorically fed groups, the circadian acrophase of cortisol being about the same in all three groups [41]. These results in Halberg's laboratory were corroborated in Paris, where circadian rhythms were shown to persist [42, 43; cf. 44] for obese human subjects on a hypocaloric diet. Thus, circadian rhythms persist in the presence or absence of food and whether food is taken iscocalorically or not, with little change in the circadian acrophase of cortisol.

\section{CIRCADIAN STAGE-DEPENDENT RESPONSE TO NUTRIENTS}

Halberg extensively documented and quantified the circadian stage-dependent response of an organism to toxins and drugs $[15-17,45,46]$, a feature that also applies to the organism's response to nutrients. This is indicated by the circadian rhythms in glucose tolerance, the rate of amino acid metabolism [46, 47-49] and the respiratory quotient, demonstrated for normally-fed and calorie-restricted women [34]. For instance, fats were reportedly utilized preferentially in the evening in resting subjects [49]. The highest respiratory quotient around noon suggests a greater combustion of carbohydrate around that time. Within-day variation in oral glucose tolerance [50] also points to a rhythm in the disposition of ingested carbohydrate, possibly related to changes in absorption, distribution and excretion, as well as in metabolism, as a result of hormonal rhythms [51, 52]. Metabolism of the amino acid tryptophan was reportedly highest during the morning in humans [53]. A circadian rhythm in the metabolism of tyrosine has also been reported in mice [54], as was a circadian variation in hepatic enzyme activity resulting from changes in dietary protein content in rats [55]. 


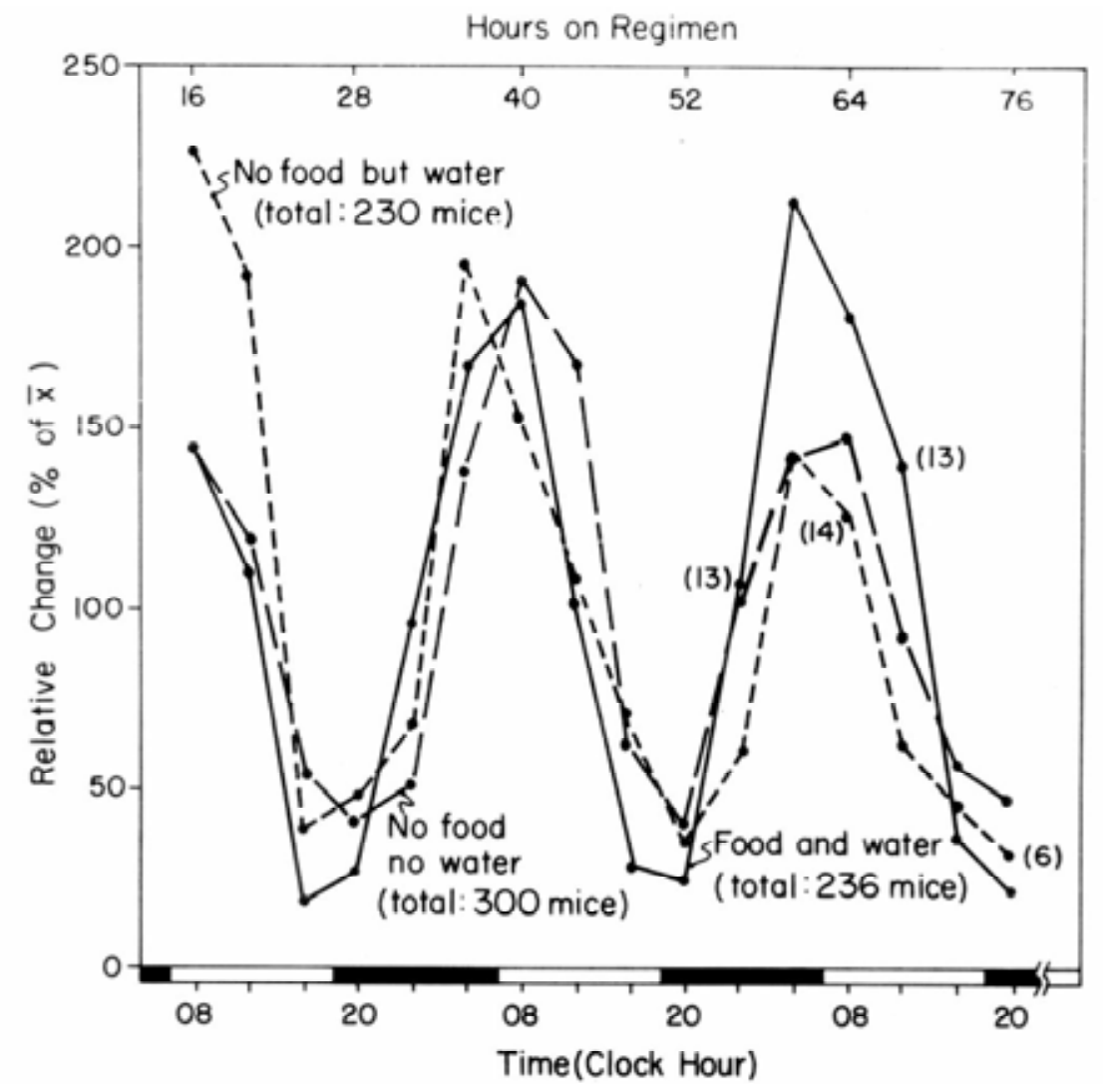

Fig. (11). Liver glycogen concentration in female $\mathrm{C}$ mice at about 4.5 months of age (15 mice per timepoint; otherwise noted in parentheses). (C) Halberg (with permission).

Despite the great variability in hepatic glycogen data collected by Franz Halberg and illustrated in Fig. (12), a reproducible circadian rhythm can be demonstrated, Fig. (13) [46]. Fig. (14) provides a map of time relations among murine circadian rhythms in carbohydrate metabolism, insulin blood concentration being in antiphase with the response to insulin of muscle glycogen [46], as originally documented by Gagliardino and Pessaq [56]. Fig. (15) shows differences in circadian acrophases of three different functional systems of mouse pancreas (cell division in the glucagon-producing $\alpha$ cells, insulin-producing $\beta$ cells and acinar cells), compared with acrophases of rectal temperature and liver glycogen, whereas Fig. (16) compares the timing of the circadian rhythm in liver glycogen with that of DNA and RNA synthesis, mitoses and phospholipids in mouse liver [46]. Figs. (17 and 18) stress the importance of accounting for the circadian system when assessing the effect of meal timing. There is an almost complete reversal of the circadian variation in both liver glycogen and in plasma free fatty acids between rats fed ad libitum and rats fed a single daily meal (from 08:00 to 12:00) [46]. Thus, the timing of daily meals affects the timing of circadian hormonal and other rhythms.

\section{CHRONOBIOLOGY AND THE DIGESTIVE TRACT}

Halberg deserves great credit for demonstrating in inferential statistical terms that the gut is built in time as well as in space. The fact that the isolated intestine can exhibit 24-hour rhythmicity was also shown by Bünning [57].
Scheving [58, cf. 59] noted that cellular proliferation in the adult male and female rodent is neither asynchronized nor random but rhythmic. Most of the murine alimentary tract shows a large-amplitude circadian rhythm, except for the duodenum, as evidenced by the incorporation of tritiated thymidine into DNA of different tissues. A circadian map shows that proliferation peaks in the second half of the dark span for tongue, with more or less progressively later acrophases for oesophagus, stomach, epididymis, testis, liver, colon, rectum, jejunum, duodenum, ileum, bladder, thymus, bone marrow, and spleen. Several tissues related to the digestive tract of the rodents peaked during the daily light span or during the second half of the daily dark span. Mitosis in the pancreas, however, qualifies the foregoing insofar as there are large differences in circadian acrophase between exocrine and endocrine tissues as well as a difference between $\alpha$ and $\beta$ cells [46], as noted earlier. Already in 1940, Hamar [60] concluded that the daily variations in glucose re-absorption from the small intestine of rats may result either from the periodic hormone secretion of the adrenal cortex or from periodicity in the sensitivity of the intestinal epithelium to cortical hormones.

In September 1981, Franz Halberg with Kirt J Vener, then Program Director for oesophageal, gastric and colonic diseases at the U.S. National Institutes of Health (NIH), organized a meeting on "Chronobiology and the digestive system" [61]. Under the sponsorship of the Division of Digestive Diseases and Nutrition of the National Institute of Arthritis, Diabetes, and Digestive and Kidney Diseases, 


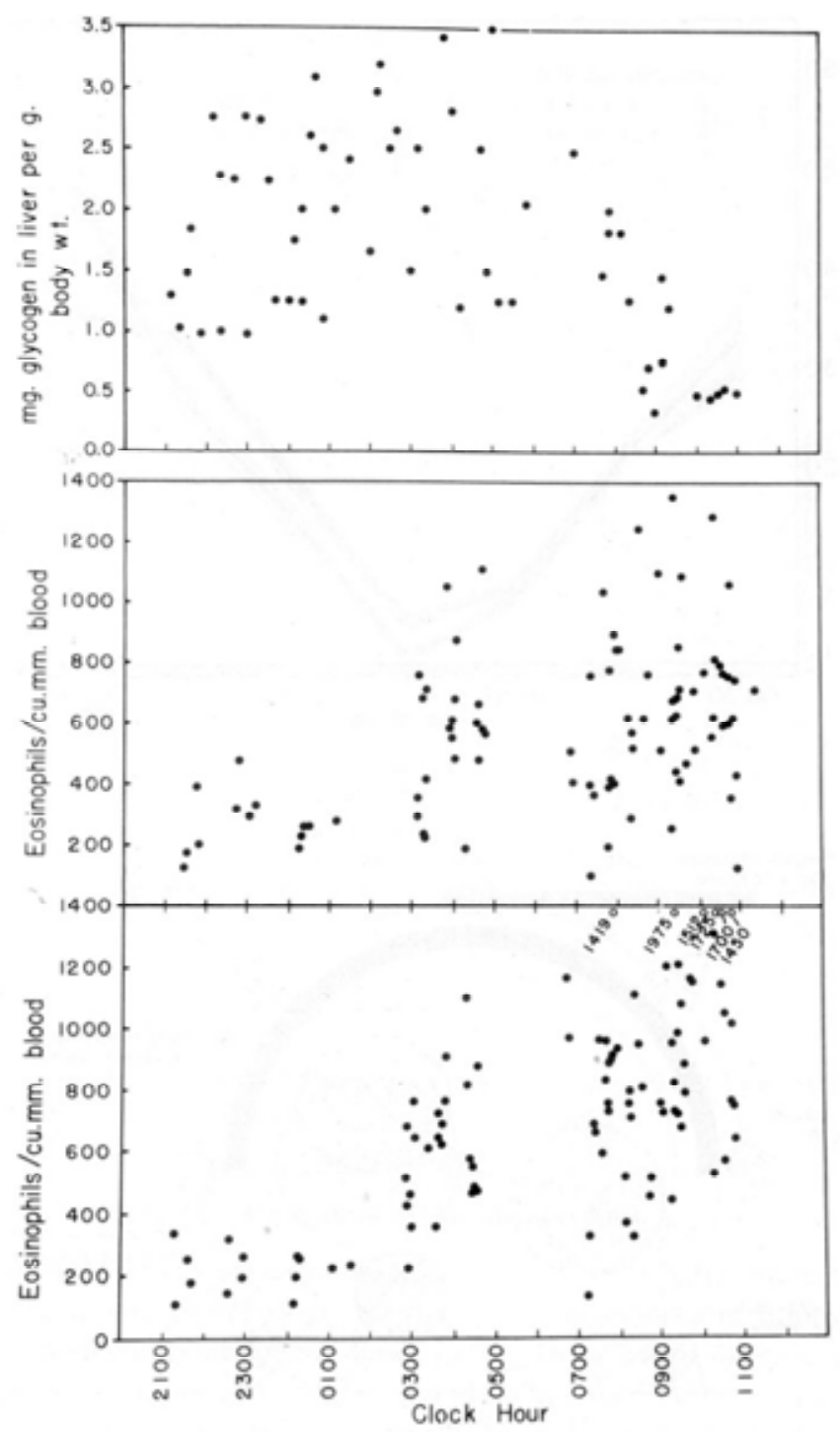

Fig. (12). Great variability is seen in data such as eosinophil counts and hepatic glycogen, from moment to moment, and as a function of circadian stage. In dealing with a statistical phenomenon, use of statistical analyses needs to complement the visual inspection of data. (C) Halberg (with permission).

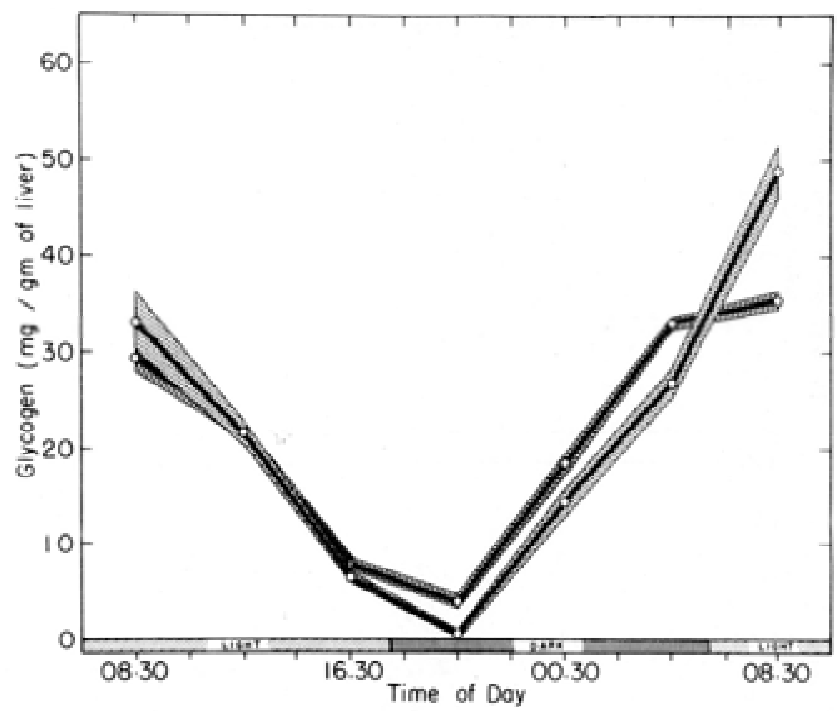

Fig. (13). Reproducibility of the circadian rhythm in liver glycogen is readily seen in time plots of mean values. (C) Halberg (with permission). 


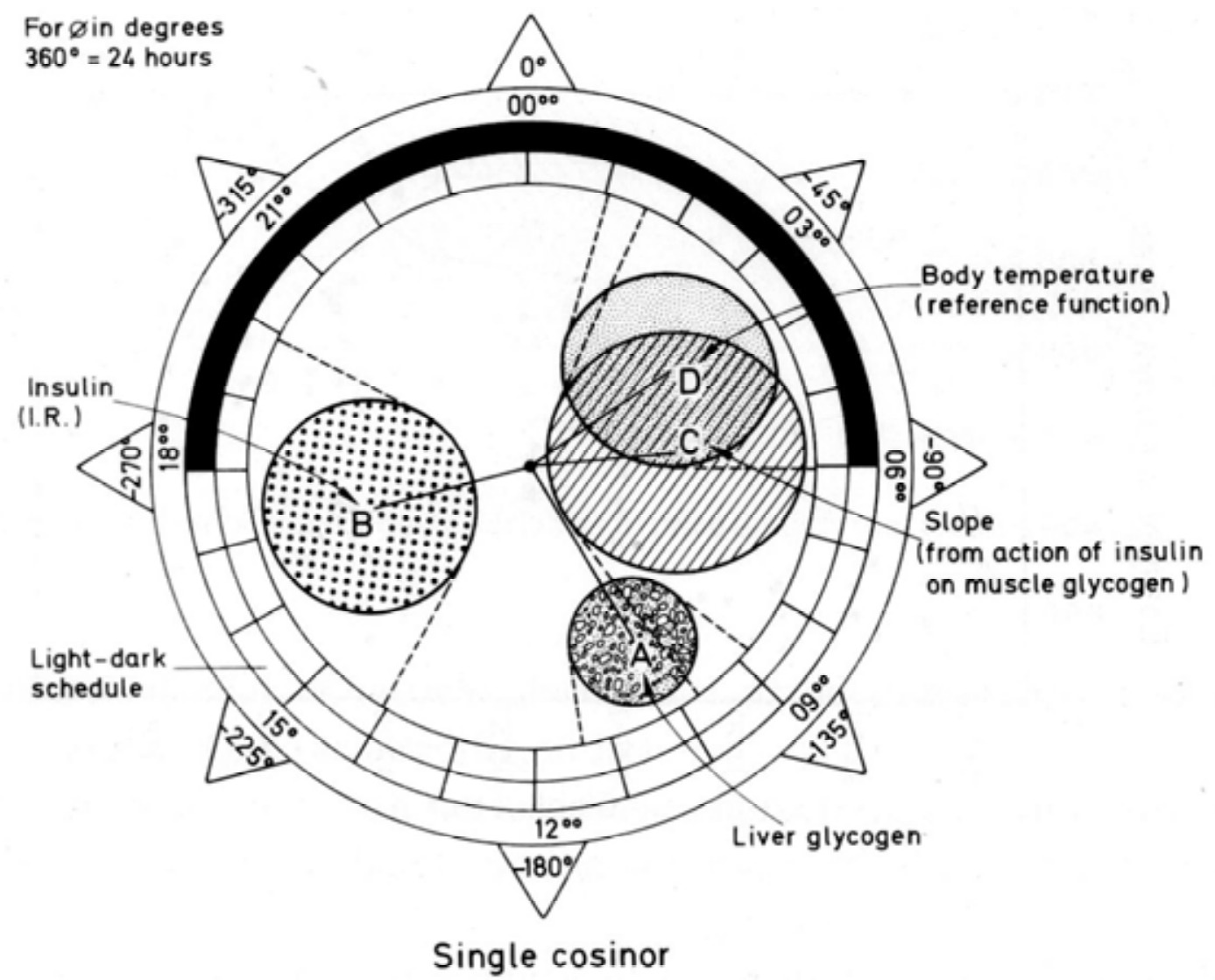

Fig. (14). Statistical significance of the circadian rhythm in liver glycogen is validated by cosinor analysis. Note antiphase between insulin and the reactivity of muscle glycogen to insulin, shown in this map of time relations among murine circadian rhythms in carbohydrate metabolism. (c) Halberg (with permission).

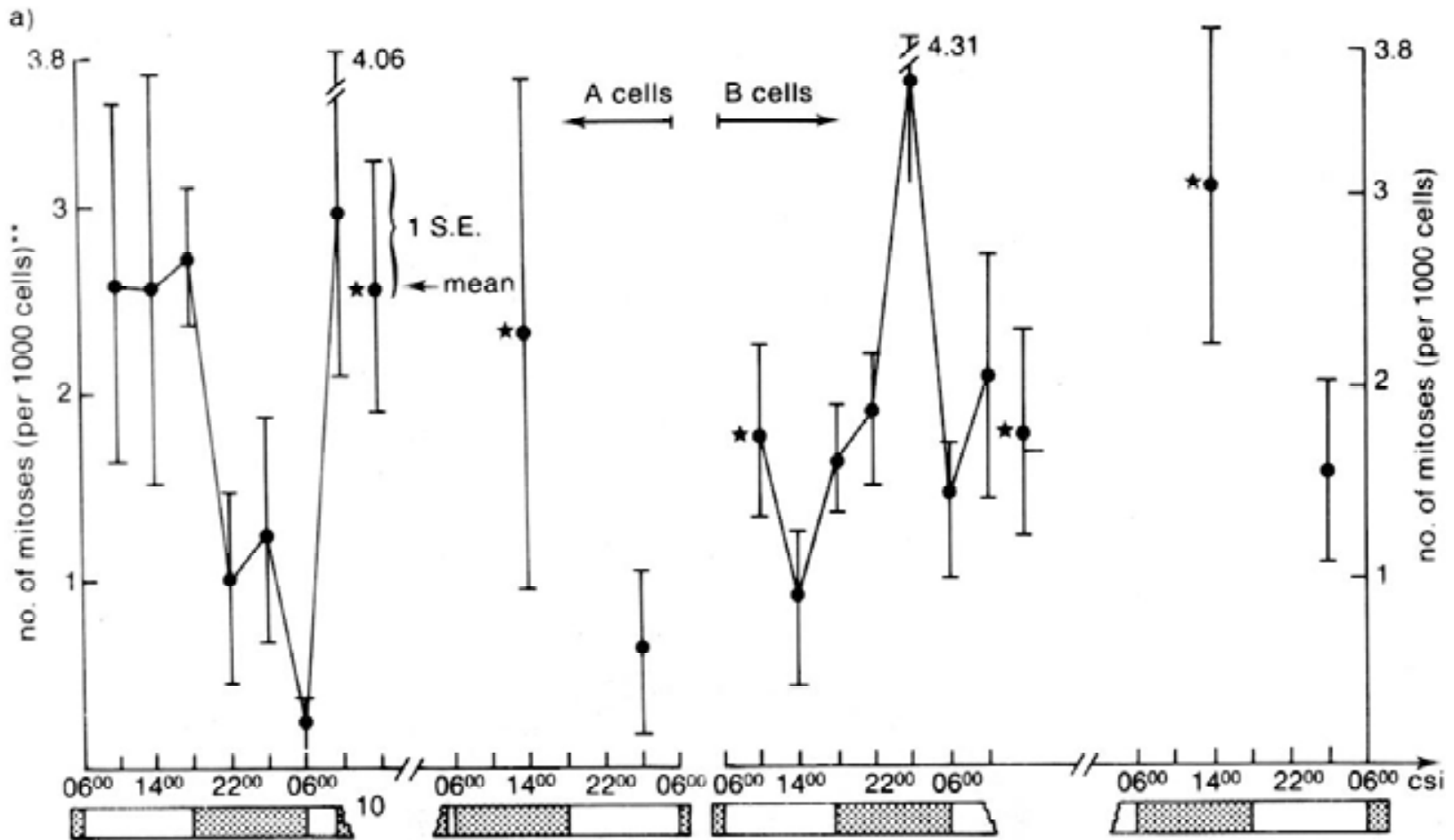

*.. male C mice - 5 weeks of age clock hours (of sampling)

** 3000 cells/pancreas 
b)

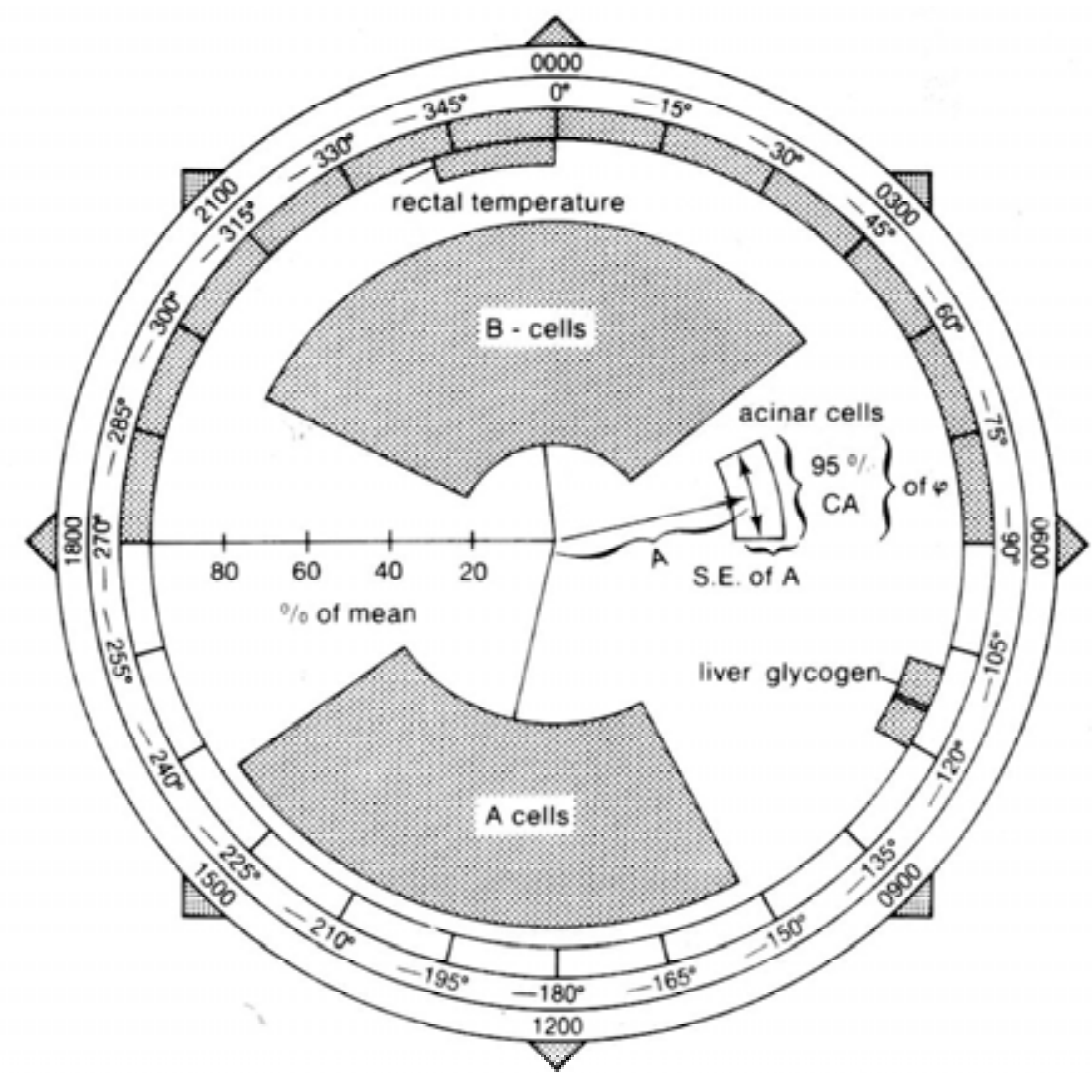

Fig. (15). Circadian acrophases of mitoses in three different functional systems of mouse pancreas, as well as of rectal temperature and liver glycogen. Rhythms with widely differing timing are found for the same variable — cell division — in the pancreas (in glucagon-producing $\alpha$-cells, insulinproducing $\beta$-cells and acinar cells of the same organ) by curve-fitting procedures (b) as well as by time plots (a). ( ) Halberg (with permission).

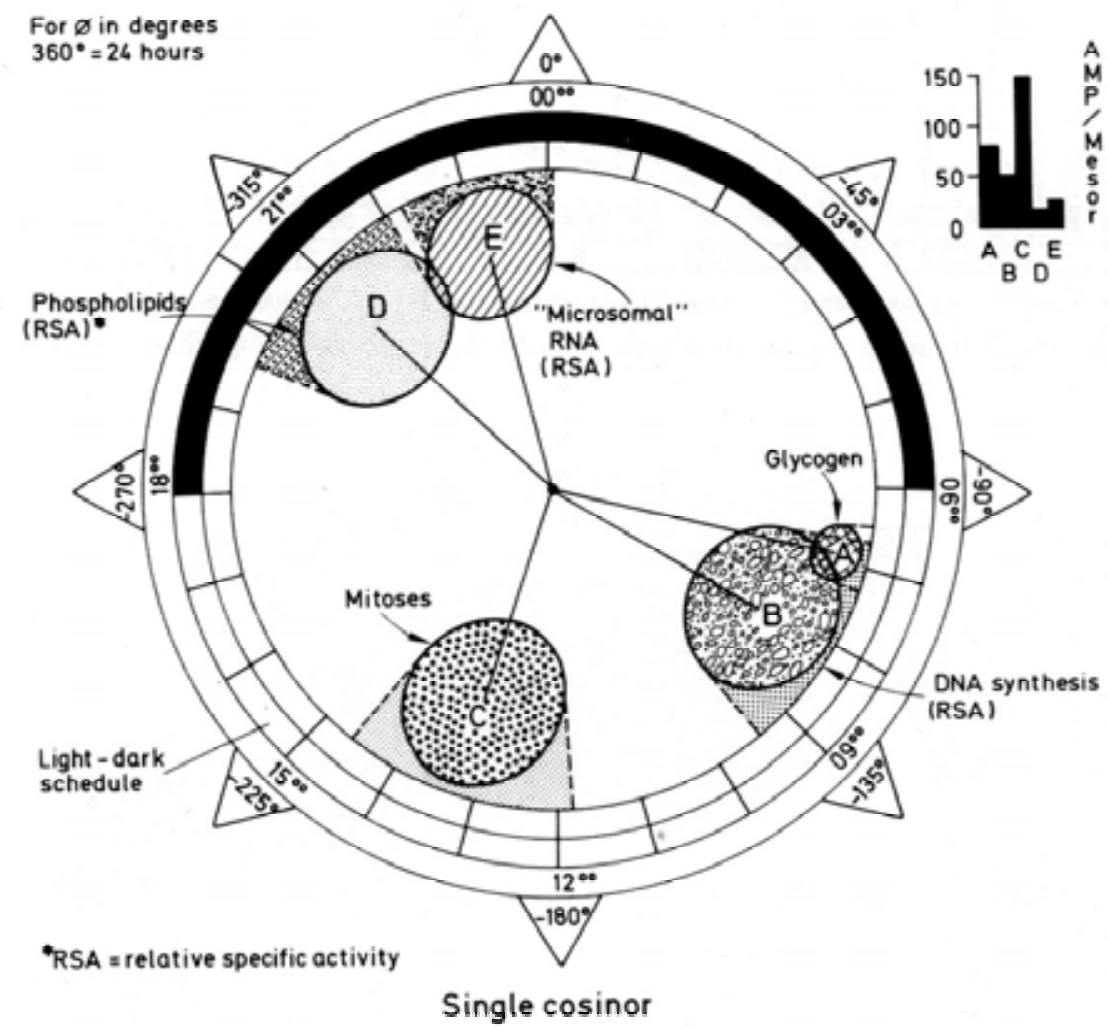

Fig. (16). Mouse liver as circadian sub-system. (C Halberg (with permission). 


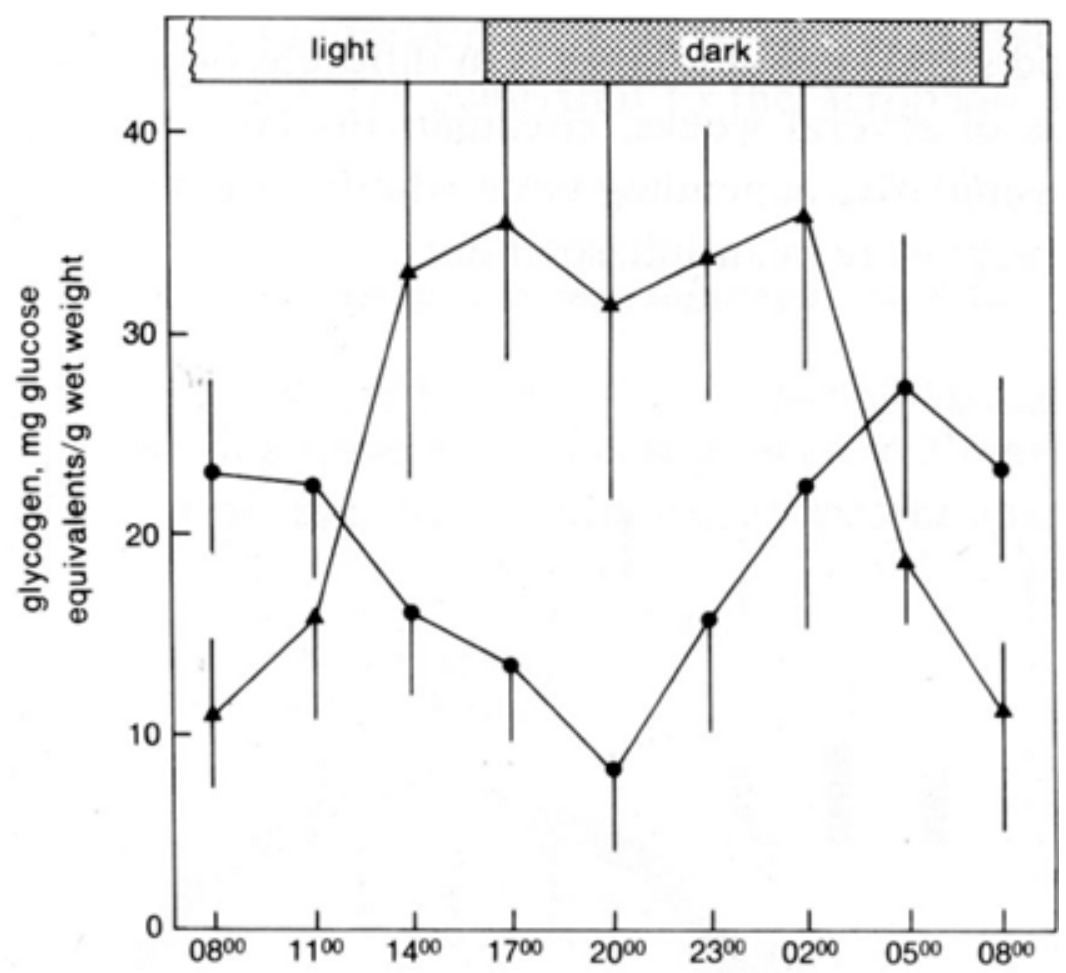

Fig. (17). Liver glycogen in rats fed ad libitum (filled circles) and in rats fed a single daily meal (08:00 - 12:00) (filled triangles). (C Halberg (with permission).

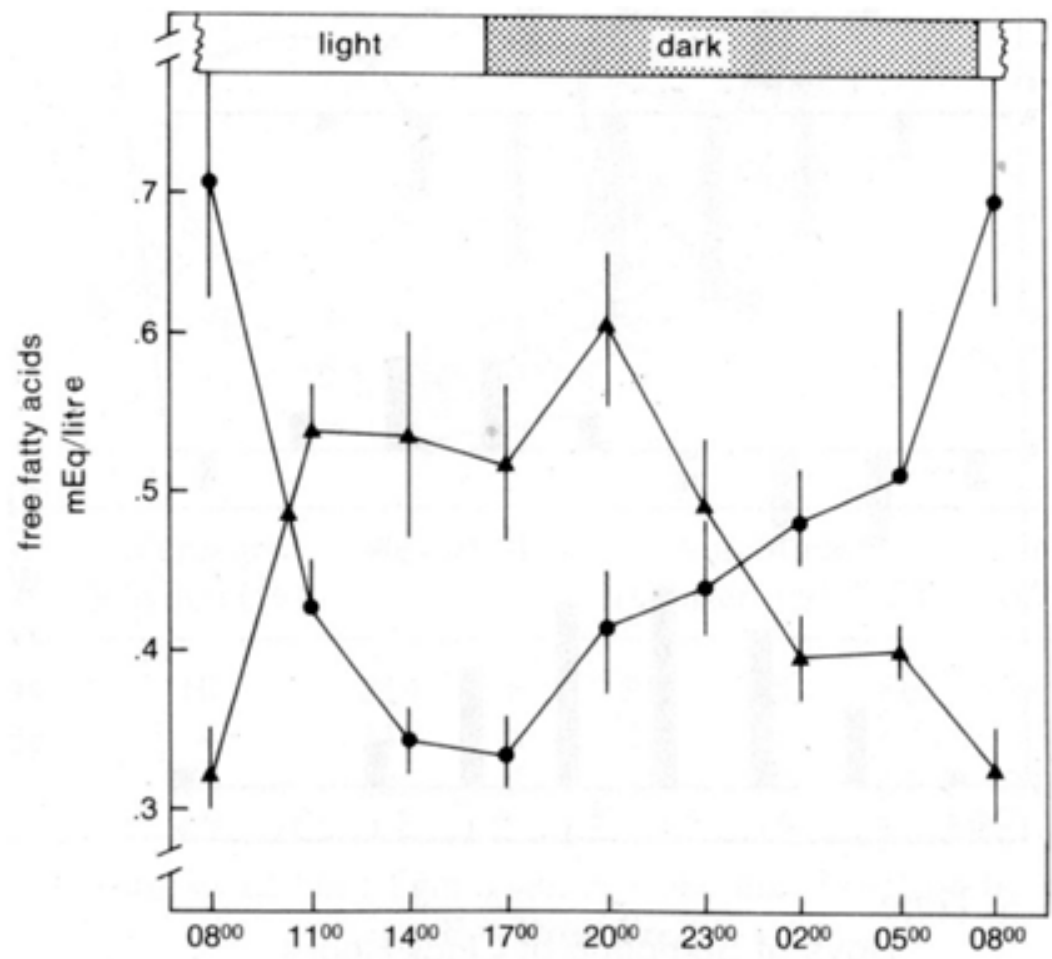

Fig. (18). Free fatty acids in rats fed ad libitum (filled triangles) and in rats fed a single daily meal (08:00 - 12:00) (filled circles). (C) Halberg (with permission).

proceedings of this meeting and of a workshop in March 1983 at the NIH were published. The proceedings included articles on feeding and intestinal digestive and absorptive time-macroscopic rhythmicity, on rhythmicity in maltase, isomaltase, sucrase, protein, and 3-0- $\beta$-methaglucoside uptake among many other variables investigated [61]. The volume also included results from flow cytometry used for monitoring cell kinetics of the gastrointestinal tract. Time- 
dependent hypersensitivity and its possible impact on bacterial digestive tract diseases, a perspective on chronoimmunology, and a gastroenterologist's perspective on chronobiological applications were some of the other topics covered [61].

Later, chronobiological work related to the digestive tract [62] documented and mapped chronomes of human gastric acidity [63-68]. The demonstration of a circadian rhythm characterizing four digestive enzymes and the inferential estimation of important differences in the timing of these rhythms required much dedication as histochemical determinations had to be done on biopsy specimens from the lower duodenum of 11 healthy men every 8 hours for 2.5 consecutive days [64]. Studies by Tarquini found differences in the circadian mitotic rhythms of the stomachs of patients with and without peptic ulcers [69, 70]. Tarquini also monitored intestinal $\mathrm{pH}$, revealing its ultradian structure [71]. A circannual rhythm in human ulcerogenesis was demonstrated by Gibinski et al. [72]. Also of clinical interest is the altered circadian rhythm in melatonin secretion in patients with duodenal ulcers [73]. Rhythm disturbances were reported both in the exacerbation and remission stages of the disease. A direct correlation between the degree of disturbance in melatonin production and the severity of the patients' clinical course was interpreted as implicating melatonin in the pathogenesis of duodenal ulceration [73].

In pigs kept in LD12:12 (lights on from 08:00 to 20:00) and fed a standard diet at 08:00, 15:00 and 22:00, pancreatic secretion in the first phase (post-prandial) exhibited a distinct meal-related pattern characterized by large amounts of protein and enzymes (trypsin and chymotrypsin). Secretions in the second phase had less protein and enzymes. During the dark span, the first phase was practically absent. The response of pancreatic secretion to the 22:00 meal was not very pronounced. Apart from the anticipated circadian rhythm, prominent 8-hour and 3.4-hour components were present, indicating that the pancreatic response to a standard meal is also circadian-stage dependent [74]. A meal given during the light span was more effective, relative to pancreatic enzyme secretion, than a meal given during the dark span [74]. Periodic fluctuations in pancreatic secretion have been related to duodenal motility in neonatal calves by Zabielski et al., [75]. Zabielski et al., [76] further noted that plasma secretin fluctuates in phase with pancreatic secretion.

In the data from Bubenik et al., [77], circadian and circaoctohoran (about 8-hour) patterns in circulating melatonin were found in the hepatic portal vein, cranial vena cava and lower aorta of 10 juvenile pigs [78]. The results indicate the relative importance of an ultradian component possibly contributed by melatonin from the intestine [78].

In the laboratory, research had led to the demonstration of a circadian stage-dependence of gastric ulcerogenesis $[79,80]$. The net result of exposure to cold, starvation and immobilization was shown to be circadian rhythmic in terms of the incidence of gastric erosions [81]. The observation that gastric emptying is also circadian rhythmic [82] is another example of the ubiquity of cycles in the digestive tract.

\section{FEEDING SCHEDULE AS SYNCHRONIZER OF CIRCADIAN RHYTHMS}

The fact that the feeding schedule may override the synchronizing effect of the lighting schedule laid the foundation of chronobiology as a discipline in its own right, as noted earlier. Much work remained to be done, however, to quantitatively determine the relative importance of both synchronizers on major organ systems, notably by mapping circadian rhythm characteristics, especially the acrophase (a measure of the timing of overall high values recurring in each cycle).

The importance of the digestive tract for timing in the organism as a whole is apparent from studies on a restricted diet. Food intake can become a dominant synchronizer of about 24-hour rhythms, e.g., by manipulating a diet with a $50 \%$ reduction in calories from carbohydrate and fat yet with the full availability of protein, vitamins and minerals, all comparable to amounts in a control diet. The time-restricted feeding can override the otherwise dominant lighting schedule. This was shown indirectly with respect to the adrenocortical cycle in Halberg's studies of blood eosinophil cells $[11,12]$, as well as with corticosterone determination. The finding that under conditions of relative starvation, the gut can override the hypothalamus has later been extended to circadian aspects of the liver, lung and pancreas [83, 84]. By contrast, in humans, changing the timing of a single daily meal shifted the circadian acrophase of cortisol only slightly, whereas it shifted certain, but not all, other variables much more.

In mice, the acrophase of certain circadian rhythms can be changed by manipulating the time when access to food is available. This was demonstrated in mice as early as 1953 by Halberg et al., [11,85] and later confirmed by Pauly et al. [86] in the case of blood eosinophil counts. Food restriction was also shown to be associated with an amplification of the circadian eosinophil rhythm, whereas the estrus cycle was abolished. The timing of access to food can be manipulated to change the timing of rhythms, even in constituents of the circadian cell cycle, such as RNA and DNA synthesis and mitosis, a result pertinent to cancer treatment [87, 88]. A manipulation of meal timing can serve a variety of purposes, such as the desiderata of a medical differential diagnosis, chronotherapy, and optimization of food utilization for performance or survival [89].

Circadian rhythms in murine core temperature, liver glycogen, serum corticosterone and corneal mitoses show a different timing and a different extent of change when daily feeding is available only in early dark or in early light [19]. In the case of the mitotic index of corneal epithelium, the circadian rhythm was shown in $360 \mathrm{CDF}_{1}$ mice to be synchronized by the lighting regimen, with only small changes in acrophase as a function of the circadian stage when mice had restricted access to food for only 4 hours [90]. Larger effects of restricted feeding schedules have been reported for other variables, notably liver enzymes [91-94], murine body temperature [95], murine corticosteroid and liver glycogen [96, 97], eosinophil counts [98, 99], and $\mathrm{CO}_{2}$ emission in rats [100]. Timing availability of food also alters functional circadian differences within intracellular morphology of rat enterocytes [101]. 
In non-human primates, the circadian rhythm in plasma triglycerides is shifted by about 7 hours when a single meal is offered either in early light or 9.5 hours later, while the shift in the circadian acrophase of skin temperature was less than 4 hours [102-105].

In humans, some circadian rhythms, such as those in insulin, glucagon and growth hormone, undergo a large shift in their timing in response to a change from breakfast-only to dinner-only, whereas other rhythms, such as that in cortisol, change only slightly [106]. In the case of plasma insulin, for instance, the circadian acrophase ranged from 13:12 to $16: 12$ (in different studies by different investigators). This is seen in obese women on a spontaneous diet or on four isocaloric meals, obese children with abnormal morning glucose tolerance, and patients with adult-onset diabetes taking glibornuride once or twice daily. A later acrophase around 19:30 was reported for patients with adult-onset diabetes before and after 30 days of glipzide therapy [46]. In 7 healthy adults consuming a single daily 2000-calorie meal, the circadian insulin rhythm peaked around 10:24 when the meal was consumed at breakfast but the acrophase was shifted to around 19:56 when the meal was consumed at dinner (Fig. 19). A similar difference was observed for glucagon (Fig. 20). As illustrated in Figs. (21-23), different variables are differently affected by meal timing [46].

A change in circadian amplitude and/or waveform is observed in other variables, such as cyclic AMP in urine [91, 107; cf. 108]. Relations among circadian rhythms in serum iron, glucagon and insulin and urinary cyclic AMP excretion differ drastically when human volunteers consume all daily

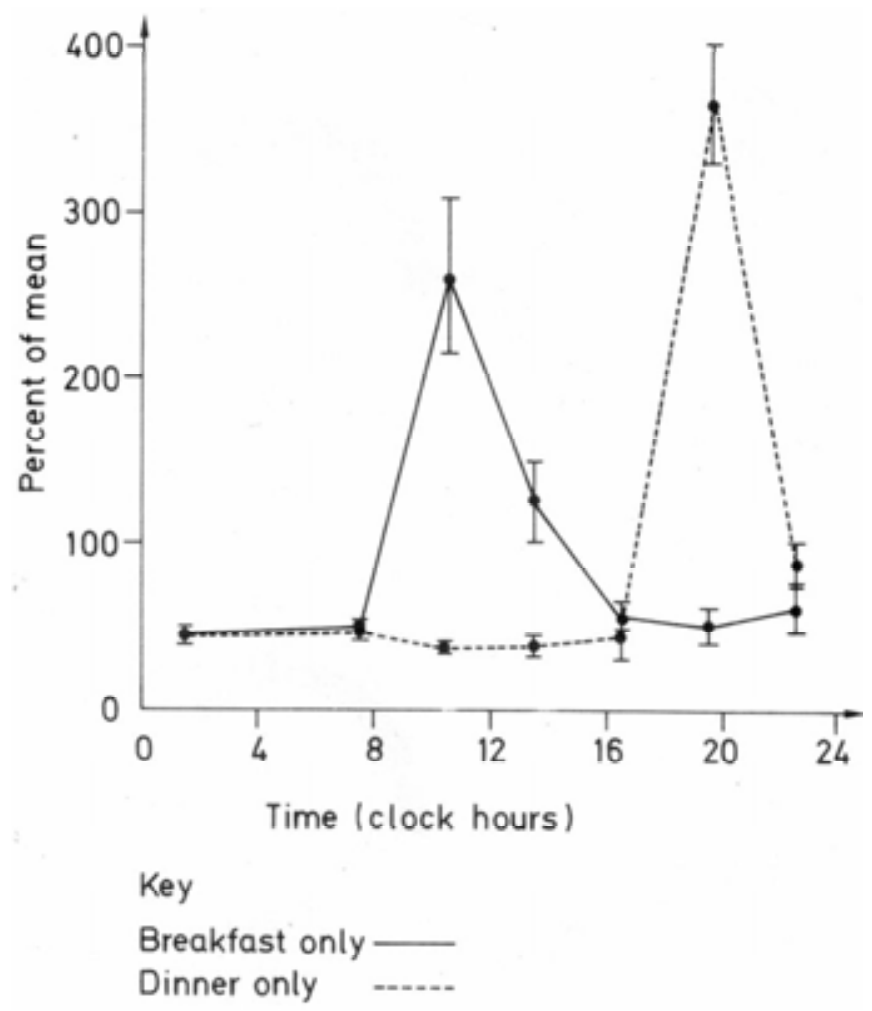

Fig. (19). Influence of meal timing on insulin (data from 7 subjects eating a single daily 2000-calorie meal as breakfast or dinner. (C) Halberg (with permission).
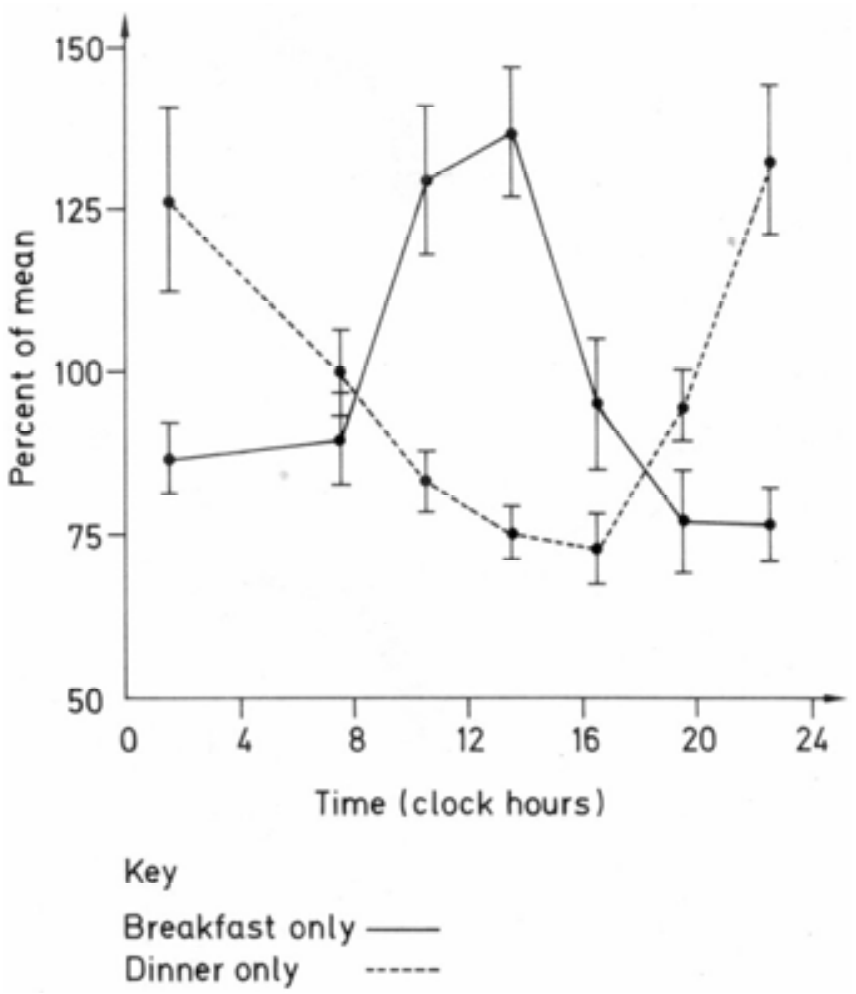

Fig. (20). Influence of meal timing on glucagon (data from 7 subjects eating a single daily 2000-calorie meal as breakfast or dinner. (C) Halberg (with permission).

food for one week as breakfast only and for another week as dinner only [109].

\section{RESTRICTED FEEDING AND LIFESPAN}

In preparation for longevity studies, it was determined that the survival of mice that were abruptly restricted to a 4hour span of daily food accessibility depended on housing density as well as on the timing of the "meal" in relation to the lighting regimen. One experiment involved 93 singlyhoused female inbred Bagg albino (BALB/c) mice kept in 3 staggered LD12:12 regimens (with lights on either from 08:00 to $20: 00,20: 00$ to $08: 00$, or $12: 00$ to $24: 00$ ) and assigned to one of 4 groups with access to food restricted to either the early part of the daily light span, the early or late parts of the daily dark span, or available ad libitum. A second study involved 92 male mice divided into 5 subgroups, 3 of which were singly-housed and the other two were housed 4 per cage. Food was freely available to one subgroup of singly-housed animals, or restricted to either the early daily light or dark span for one singly-housed and one multiply-housed subgroup. Whereas all mice fed ad libitum survived, survival time was shortened in singly-housed foodrestricted mice, more so when food accessibility was during the daily light (rest) span than when it was during the daily dark (active) span. All multiply-housed mice survived, even though their food availability was similarly restricted [110].

A lifespan study of meal timing and circadian rhythms [111] in $\mathrm{CD}_{2} \mathrm{~F}_{1}$ mice investigated the possibility that alteration in circadian rhythm characteristics contributes to the life-prolonging effect of food restriction. Mice kept on a 

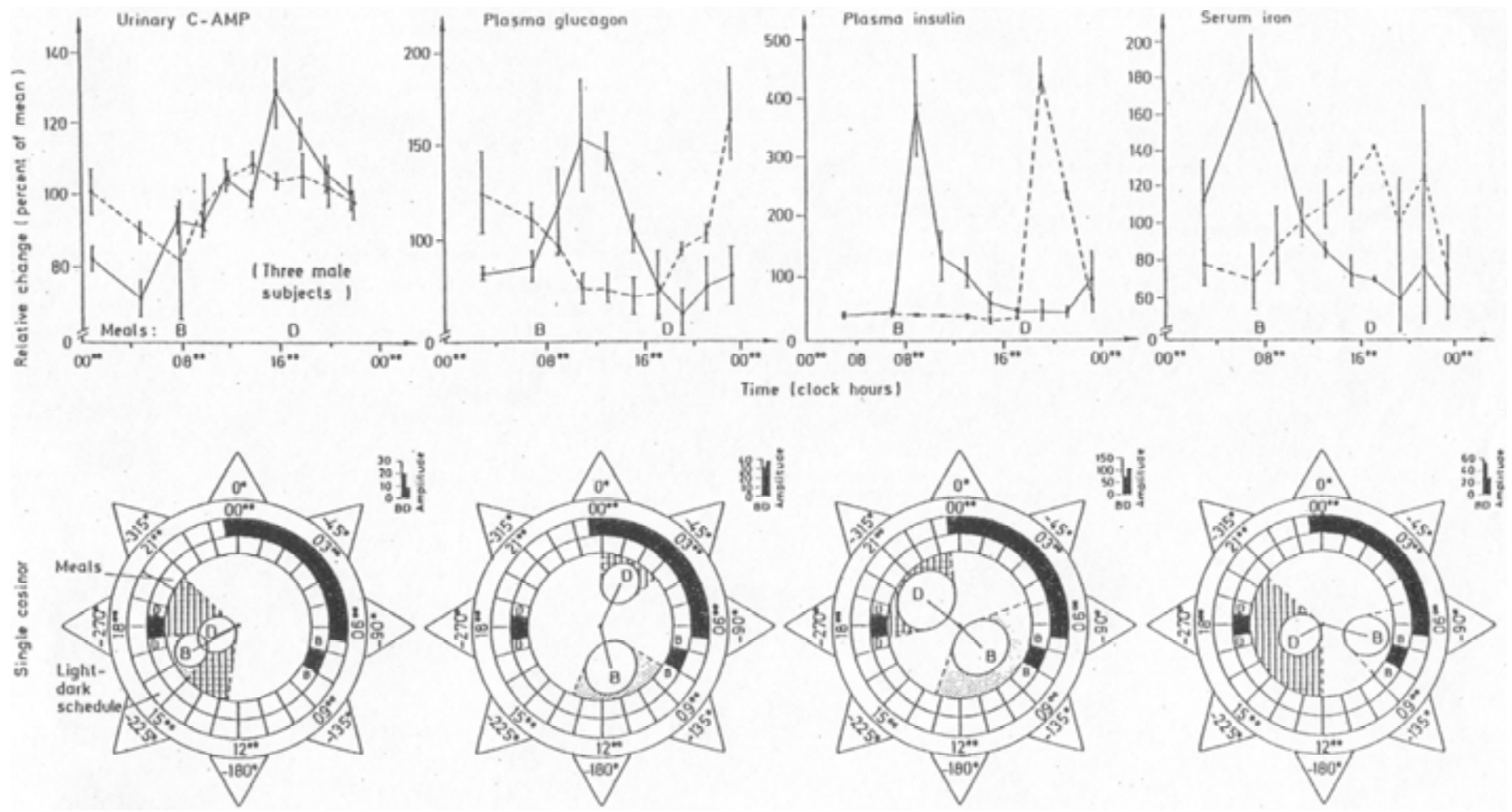

Fig. (21). Meal schedules modify internal relations of human circadian rhythms. (C) Halberg (with permission).
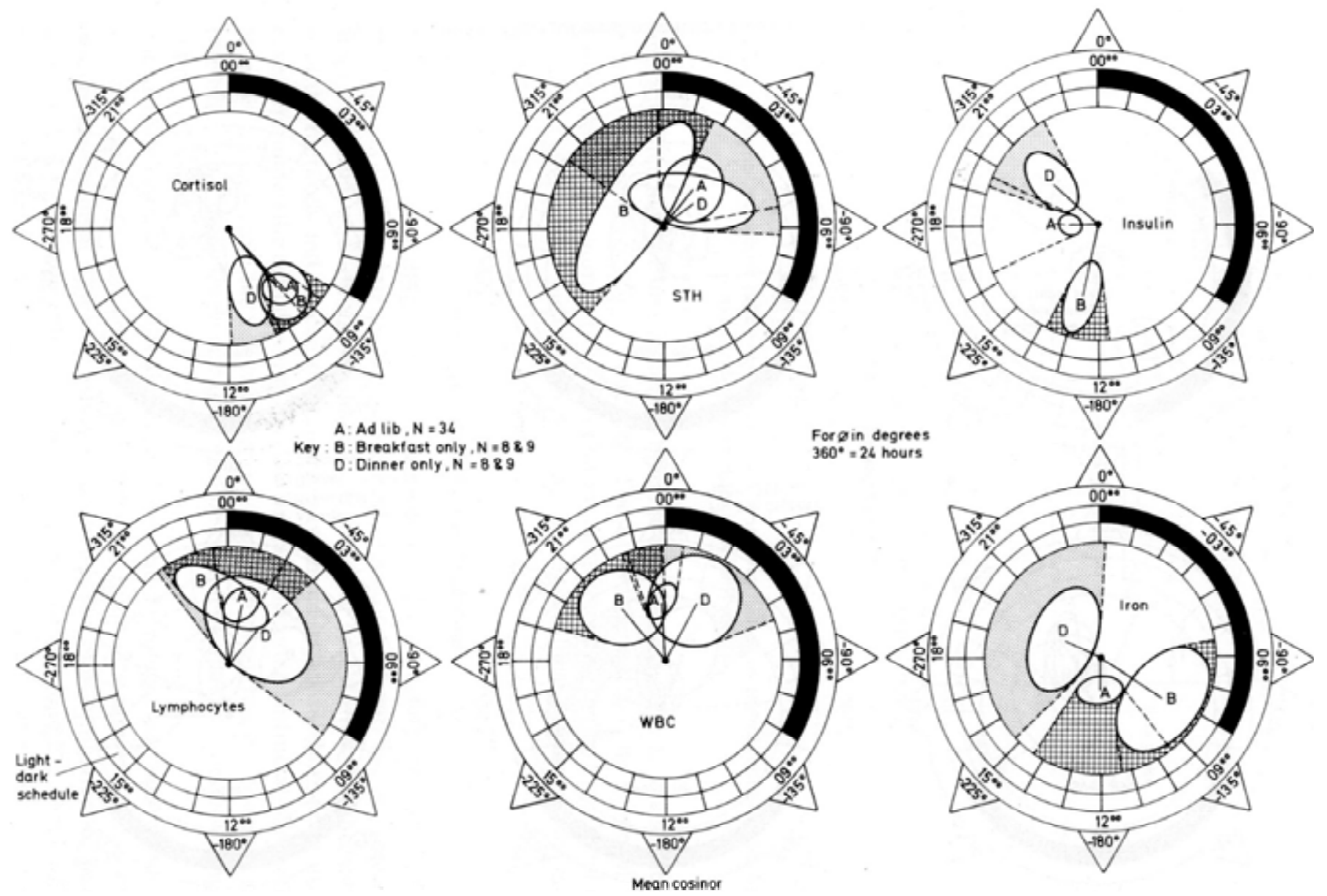

Fig. (22). Meal scheduling modifies internal circadian timing in human blood. () Halberg (with permission). 

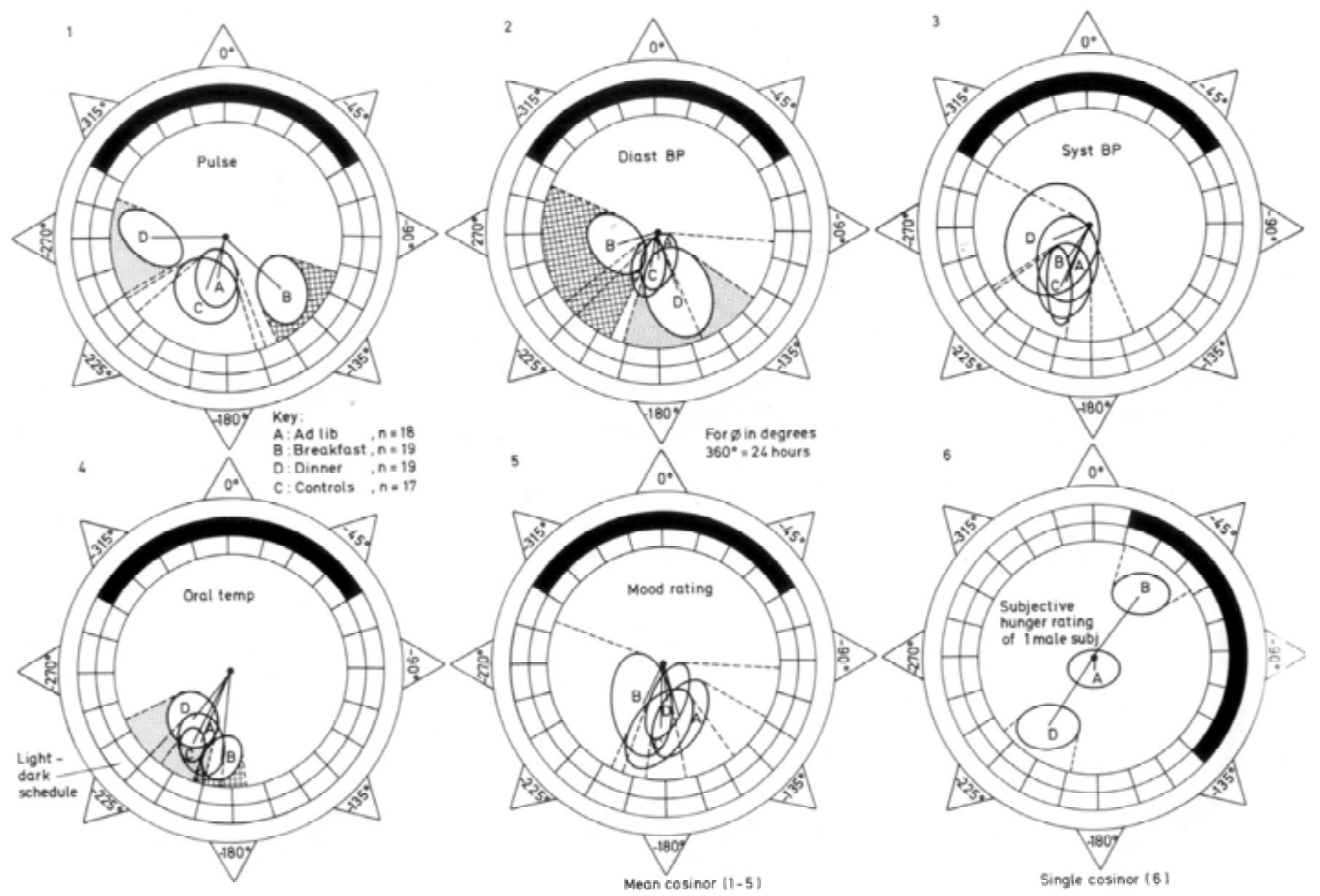

Fig. (23). Different effects of meal scheduling on human circadian rhythms. (C) Halberg (with permission).

lighting regimen of 12 hours of light alternating with 12 hours of darkness were either fed ad libitum or were subjected to a lifelong restriction of about $75 \%$ of ad libitum intake, starting at 6 weeks of age, using a special apparatus for automatically timing access to food [112]. The daily schedule of food accessibility consisted of a single meal during the early dark (active) span, a single meal during the early light (rest) span, or six smaller meals at about 2-hour intervals during the dark span. Food restriction prolonged life, as documented in earlier studies [12]. Mammary tumors appeared sooner and were more prevalent in the group fed ad libitum than in the restricted groups. No difference was found, however, among the three feeding-restricted groups in terms of lifespan, $10^{\text {th }}$-decile lifespan, or tumor incidence. Factors possibly contributing to the prolonged lifespan suggested by this study were a lower body temperature, a reduced overall metabolic rate, and an increased circadian amplitude, revealed in all three restricted groups by telemetry of body temperature [113].

In order to separate the possible role of rhythm alteration from that of food restriction per se underlying the reduction in cancer incidence and the prolongation of lifespan associated with caloric intake, female $\mathrm{CD}_{2} \mathrm{~F}_{1}$ mice kept in light and darkness alternating at 12-hour intervals were randomly assigned to three different feeding schedules: ad libitum, meal feeding in early dark, and pattern-feeding. In the latter group, food was accessible for several shorter spans, mostly during the dark span, adjusted to maintain food intake at about $75 \%$ of the ad lib intake without increasing the circadian amplitude in body temperature beyond that of ad lib mice [114, 115]. Whereas food restriction prolonged lifespan, no difference in average lifespan or $10^{\text {th }}$-decile lifespan was found among the differently restricted groups [116]. There are marked differences in the circadian pattern of telemetered body temperature as a function of meal(s) scheduling. This suggests that the effect of food restriction on lifespan is probably not due to altered relations among circadian rhythms. Possible contributing factors suggested by this study were again a lower body temperature, a reduced overall metabolic rate and an increased circadian amplitude [111, 116].

Weekly 12-hour shifts of the daily light-dark schedule for a lifetime did not affect mean survival time of mice fed ad libitum. Shifts of the lighting regimen of meal-fed mice were implemented alone (fixed meal-time) or in combination with a corresponding shift of feeding time (to always occur during the dark, active span). Telemetered core temperature data indicated marked differences in response to the different shift conditions and suggested, in the case of meal-fed animals, involvement of a food-anticipatory rhythm [117]. Shifting of the lighting regimen had no statistically 
significant effect on mean survival time of mice feeding ad libitum, regardless of the age when shifts were initiated [117]. Whereas meal feeding was associated with prolonged lifespan, the added imposition of schedule shifts did not statistically significantly alter mean survival time [117]. When the availability of food as a single meal alternated between the light and dark spans, there was a statistically significant increase in the $10^{\text {th }}$-decile survival time [117] and a statistically significant decrease in mammary tumor incidence [118].

\section{RESTRICTED FEEDING AND CANCER}

Halberg's lifespan studies of food restriction in mice gave him an opportunity to revisit the role of nutrition in cancer. Early on, he showed that in ovariectomized and calorie-restricted mice, the circadian rhythm in blood eosinophil counts, a marker of adrenal cortical function before the advent of steroid assays, increased in amplitude, being accompanied by a marked reduction in breast cancer incidence [119]. In addition to the reduction of estrogens that promote breast cancer, there is a shift of steroid synthesis to mitosis-inhibiting corticosteroids associated with caloric restriction. Halberg postulated that this may underlie a further reduction in breast cancer incidence, adrenal cortical amplification constituting a putative mechanism inhibiting mammary carcinogenesis [120].

$\mathrm{He}$ also reasoned that manipulating meal timing in relation to the rest-activity schedule could be exploited to optimize the efficacy and safety of treatment. The restriction of feeding to the first 4 hours of the habitual daily rest span was shown to shift the rhythm in susceptibility of mice to a carcinostatic drug, adriamycin, regardless of whether the dose was fixed or adjusted to body weight $[41,121]$.

Inbred Lou/M/Wsl rats bearing a transplantable immunocytoma and treated with adriamycin had a longer survival time when meal-fed for 2 hours in early light (rest) as compared to rats feeding ad libitum [122, 123]. The prolongation of survival by meal feeding in early light may be partly accounted for by a relative acrophase shift of the circadian rhythms in the host (rectal temperature, shifted markedly) and tumor (immunoglobulin excretion, no marked difference in timing), and by the fact that meal-fed rats consumed less food [123, 124].

Alternate-day feeding of $\mathrm{C}_{3} \mathrm{H}$ mice, which develop spontaneous mammary tumors, has also been associated with a prolongation of mean survival time and a reduction in breast tumor incidence [125-127]. Circadian rhythms in body weight, urine volume and intraperitoneal temperature persisted during alternate-day feeding, but with altered rhythm characteristics. Reduction in total food intake was shown to be responsible for inhibiting the development of autoimmune disease in $\mathrm{B} / \mathrm{W}$ mice [128]. Diets low in fat and high in protein and fiber content reportedly led to delayed development of autoimmunity and prolonged lifespan of NZH mice of both sexes, while the restriction of protein intake alone did not produce the same effect but still benefited T-cell functions [128].

A dampened circadian variation in several lipid peroxides and other anti-oxidants (malondialdehyde, superoxide dismutase, catalase, glutathione peroxidase, glutathione reductase, HDL, ascorbic acid and uric acid) was associated with gynecological malignancies $[129,130]$. The MESOR of malondialdehyde is higher in patients with gynecological malignancies than in healthy controls and it is also elevated in patients with non-insulin-dependent diabetes mellitus, with an enhanced circadian variation [129].

\section{CALORIE RESTRICTION AND BLOOD PRESSURE}

Effects of salt and calorie restriction upon circadian rhythms in blood pressure and heart rate were individually assessed in 13 men [131]. A reduced blood pressure MESOR during the salt restriction stage was found in only $50 \%$ of the subjects complying with the protocol. By contrast, blood pressure was lowered in most subjects in association with calorie restriction [131]. Whereas, as expected, in some subjects, sodium restriction was associated with a decrease or no statistically significant change in blood pressure, Halberg discovered the existence of another group of subjects who actually increased their blood pressure in response to sodium restriction in this study $[132,133]$ as well as in a prior study carried out at the National Institutes of Health [134]. His results were soon corroborated by another investigation and independently validated in a study of salt loading wherein a subpopulation of subjects was found to have a statistically significant decrease in blood pressure [135].

The circadian stage-dependent effect of sodium intake on blood pressure was later demonstrated in a study of 7 clinically healthy normotensive women who monitored their blood pressure around the clock for 2 days in three stages of 1 week each, namely their usual distribution of dietary salt among the three daily meals, $2 / 3$ of dietary salt at lunch time, followed by $2 / 3$ of dietary salt at dinner time [136]. Whereas, on the average, the blood pressure MESOR increased when $2 / 3$ of dietary salt was taken at lunch time, it decreased when 2/3 of dietary salt was taken at dinner time [136].

A recent meta-analysis of data from randomized, controlled trials questions the wisdom of reducing dietary salt intake across the board, finding no convincing evidence for a beneficial effect of salt restriction on mortality, but rather an increased risk of all-cause mortality in patients with heart failure [137]. The effect of moderate reduction in salt and calorie intake on urinary aldosterone and other related variables was extensively studied by Cugini et al. [138, 139].

\section{MEAL TIMING AND WEIGHT GAIN OR LOSS}

Problems related to food consumption are as acute today as they were in August 1975 when meal schedules and their interaction with the body's schedules [20] were reviewed at the Xth International Congress of Nutrition in Kyoto, Japan $[19,88,140,141]$. Economy can be achieved by limiting the number of meals as well as by reducing meal size.

In areas where only one meal a day can be afforded, it is important to find ways in which reduced daily caloric intake can be made to contribute most efficiently to the metabolic needs associated with the performance of routine body activities [20]. Since the timing of a meal or meals can have important effects on the body in health and disease, optimal 
nutrition requires a consideration of when food is consumed [20].

It seems possible to better exploit what is being eaten by scheduling meals. Food consumption could be scheduled for a time when it is physiologically [18, 30, 44, 46, 142, 143] and logistically most useful for body weight maintenance. Several investigations by Franz Halberg and coworkers have shown a relative gain in body weight when a single daily meal is consumed at dinner versus breakfast. These results still await exploitation whether concerns are for adequate body weight maintenance in under-nourished populations or for problems of under-consumption of rations by workers in the field, such as soldiers [21].

In two separate studies of the effect of meal timing on body weight, 9 men and 9 women consumed either a fixed $2000 \mathrm{kcal}$ meal or a single free-choice meal as breakfast (B) or dinner (D). Study stages lasted 1 or 3 weeks, respectively. During the reference stage, subjects ate whenever and as much as they wanted from a wide selection of frozen or canned food rations. They self-measured and self-rated a number of variables every few hours during wakefulness during the entire study [144]. As seen in Fig. (24), body weight remained more or less unchanged on dinner only. A decrease of about $1 \mathrm{~kg}$ /week was noted on breakfast only. The rate of body weight change also differed between the two schedules $(\mathrm{P}<0.01)$. As seen in Fig. (25), only one volunteer gained weight on breakfast versus dinner. Overall, the difference in relative body weight loss on breakfast versus dinner is statistically significant $(\mathrm{P}<0.05)$, whether a fixed $2000 \mathrm{kcal}$ meal or a single free-choice meal is consumed. Weight change was calculated as weight on dinner-only subtracted from weight on breakfast-only. Also apparent from Fig. (26) is that the mean relative weight loss on breakfast only was greater on a fixed $2000 \mathrm{kcal}$ meal than on a free-choice meal. This result suggests that appetite (defined as choice and amount of food consumed) modifies the effect of meal timing on body weight. As seen in Fig. (27), the lesser body weight loss on breakfast versus dinner observed on a free-choice versus a fixed $2000 \mathrm{kcal}$ meal occurred while calorie consumption on the free-choice meal was less (not more) than $2000 \mathrm{kcal}$ per meal.

Catfish also show more or less body weight gain depending on the circadian stage when food is offered [145]. On the average, in two experiments, catfish on restricted feeding schedules (in early dark, late dark, early light or late light for 45 to 50 days) gained in body weight but more so when fed in late dark than in late light. Body weight gain in the presumably dark-active catfish seems to be maximal when food is made available in the middle or later part of the daily dark span [145].

\section{MEAL TIMING AND CIRCADIAN TIME STRUCTURE}

In a crossover study, 14 clinically healthy men consumed 60,30 and $10 \%$ of daily calories on their usual diet at breakfast, lunch and dinner for a 3-week span, while during

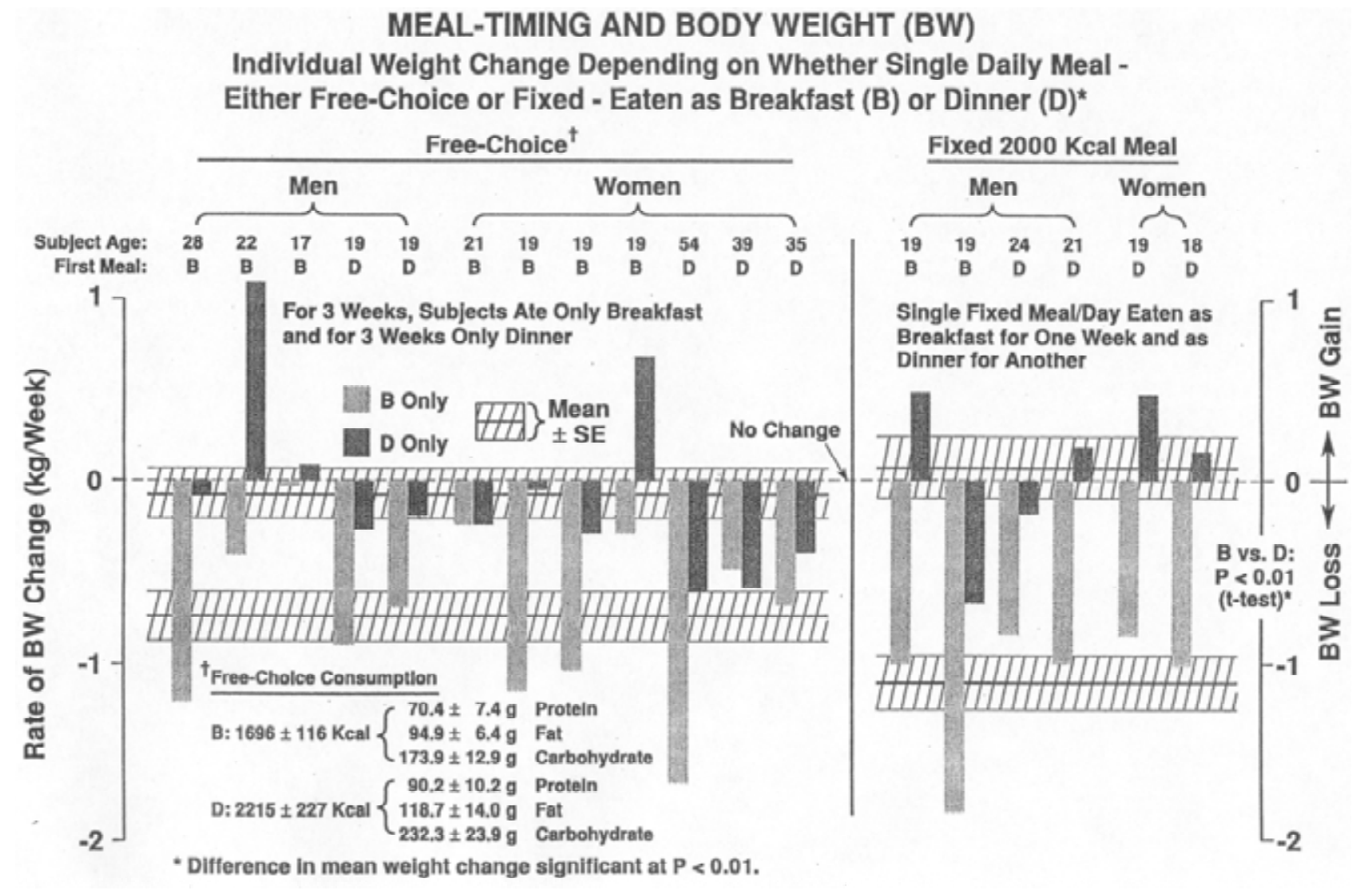

Fig. (24). The rate of body weight change, i.e., the extent of overall relative body weight loss on breakfast-only vs. dinner-only, differs significantly $(\mathrm{P}<0.01)$ between the two schedules. $($ C Halberg (with permission). 


\section{MEAL-TIMING AND BODY WEIGHT}

Relative Body Weight Loss for Individuals Consuming

\section{Single Daily Meal (Free-Choice or Fixed) as Breakfast (B) or Dinner (D)*}
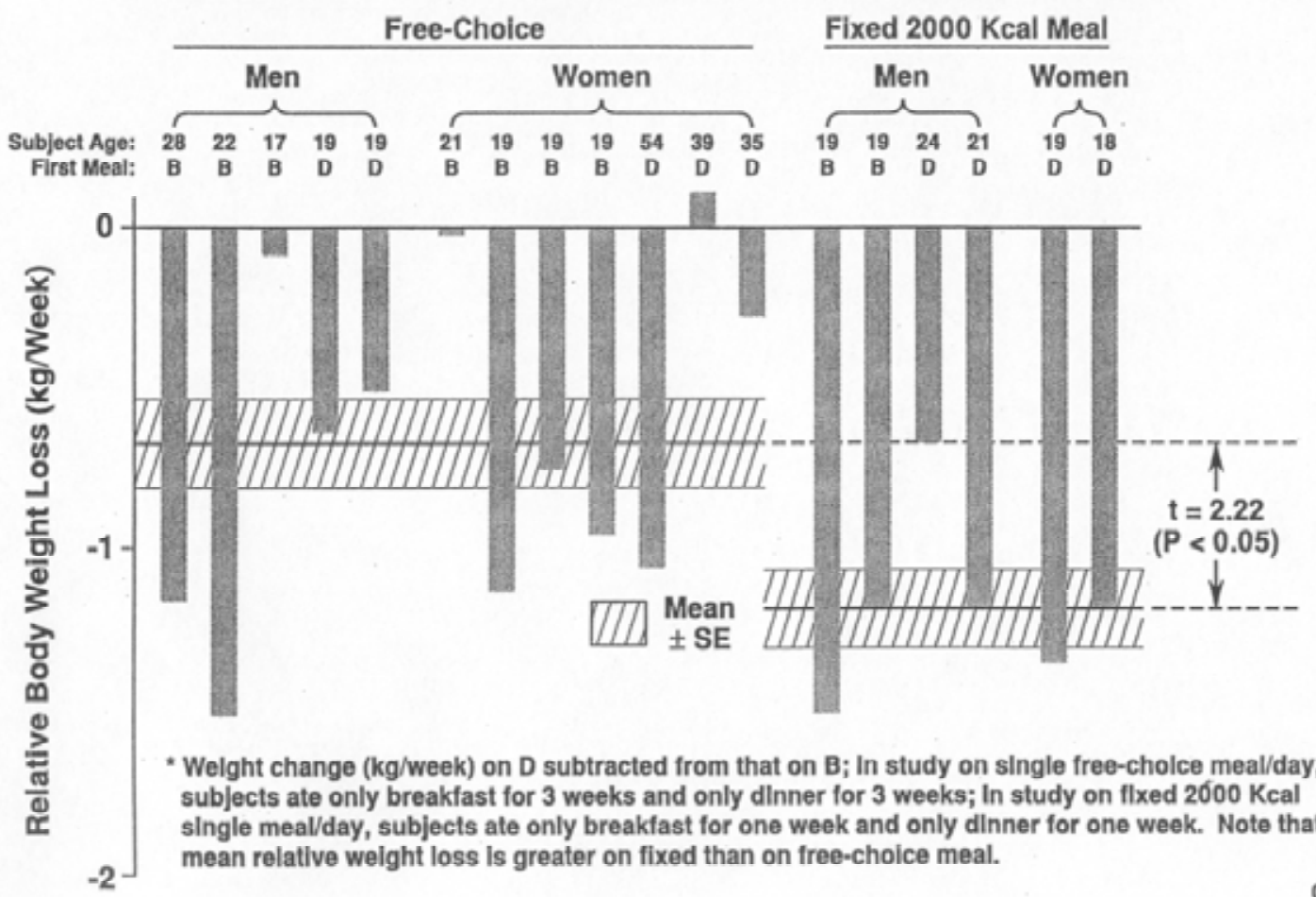

CC 10.

Fig. (25). In two separate studies on the effect of meal timing on body weight, a total of nine men and nine women consumed, some a fixed $2.000 \mathrm{kcal}$ meal for 1 week, others a single free-choice meal for 3 weeks as breakfast-only (B) or as dinner-only (D). Body weight remained more or less unchanged on dinner only. A decrease of about $1 \mathrm{~kg} / \mathrm{wk}$ was noted on breakfast only. When eating just a single meal within one hour of awakening (breakfast-only, gray bars) or not before 12 hours after awakening (dinner-only, black bars), with only one exception (subject 39), there is a relative body weight loss on breakfast-only as compared to dinner-only. (C) Halberg (with permission).

another 3-week span, the distribution of calories was reversed [146, 147]. Blood samples were taken every 4 hours during 24 hours. Meal timing was found to completely synchronize some variables related to energy metabolism, either completely (such as plasma triglycerides) or partially (such as plasma cholesterol, pancreatic and total glucagon, VLDL components, proteins, phospholipids, blood glucose, NEFA and ketone bodies, and insulin). Redistributing the proportion of food at conventional meal times thus results, for the same amount of the same nutrients, in changes of the fluxes through the metabolic pathways [146-148]. Whereas the shift in the circadian acrophase of insulin is similar in this study to that found after a change between breakfast only and dinner only, the circadian amplitude is larger in the latter study [148].

These results are in keeping with those observed in subjects eating a single daily meal either at breakfast or at dinner, by comparison to their time structure during an initial reference stage during which they ate at will, and also by comparison with another group of subjects who followed their usual routine [21, 144]. The circadian acrophase in body core temperature showed relatively good stability. Interestingly, this was also the case for a physician with aldosteronism treated with spironolactone and earlier with chlorothiazide, whether he manipulated the timing of meals in the face of an unchanged drug schedule, the timing of medications in the face of an unchanged meal schedule, both

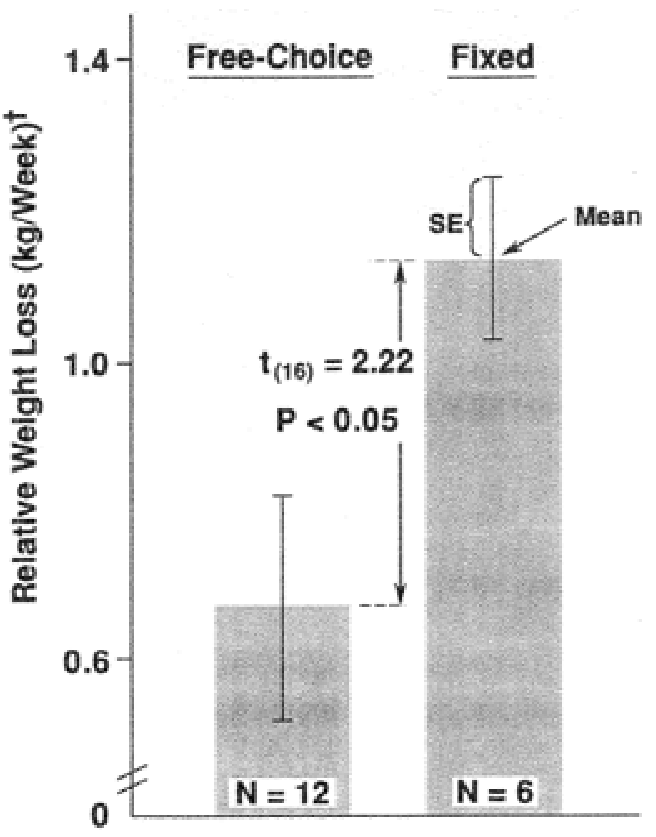

Fig. (26). Appetite (here defined as choice and amount of food) modifies the effect of meal timing on body weight. Relative body weight loss on breakfast-only (B) as compared to dinner-only (D) is less when meal is free choice rather than fixed. (C) Halberg (with permission). 


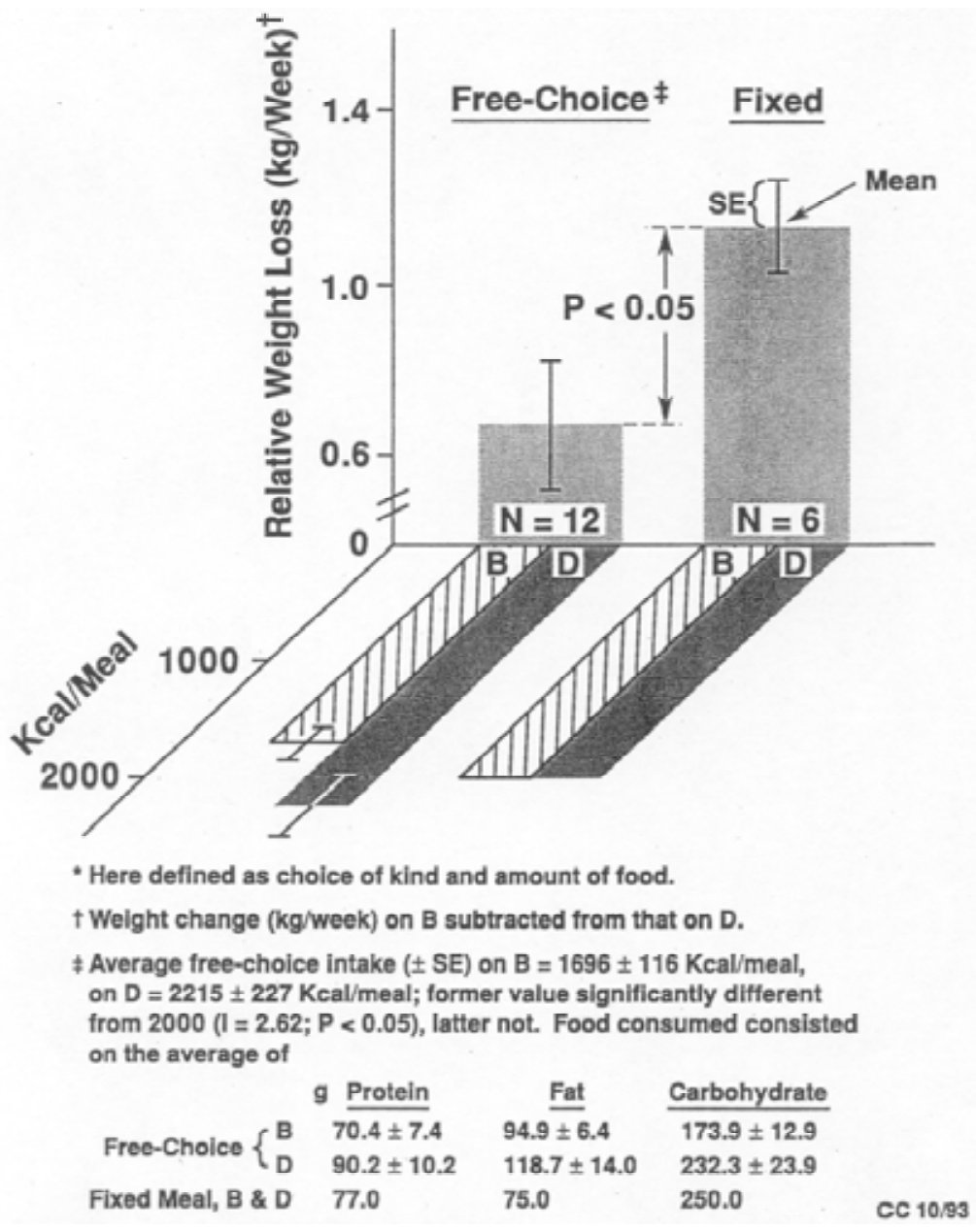

Fig. (27). Appetite (here defined as choice and amount of food) modifies the effect of meal timing on body weight. The lesser body weight loss on breakfast (B) versus dinner (D) observed on a free-choice versus fixed $2000 \mathrm{kcal}$ meal occurred while calorie consumption on the free-choice meal was less (not more) than $2000 \mathrm{kcal}$ per meal. (C) Halberg (with permission).

his overall meal and activity routine, with or without geographic displacement across time zones [144]. Circadian rhythms with similar acrophases were found on all four schedules for right and left grip strength, finger counting, adding speed, vigor and mood. By contrast, heart rate showed an advance in acrophase on breakfast only and a delay on dinner only, and the circadian acrophase of diastolic blood pressure was delayed by breakfast rather than by dinner [144].

In yet another study, 9 male students were kept under controlled physical experimental conditions for 72 hours, sleeping from 00:00 to 07:00 on the first day and from 12:00 to $19: 00$ on the third day, not sleeping at all on the second day. Meals were at the same times during all 3 days. The circadian acrophase changed only little from day 1 to day 3 in the case of oral temperature ( 2 hours and 16 minutes) and urinary cortisol (roughly 1.5 hours), but markedly for systolic and diastolic blood pressure (almost 12 hours) and with intermediate results for several urinary variables such as volume, chloride, sodium and potassium [149, 150].

\section{PUTATIVE MECHANISMS UNDERLYING LIFESPAN PROLONGATION BY FOOD RESTRICTION}

A long series of lifespan studies on rodents in Halberg's laboratory led to the postulate that a lower body temperature, a reduced overall metabolic rate and an increased circadian amplitude could be the underlying mechanism by which longevity is increased by energy restriction [111, 151]. Already by 1952 , a restriction in dietary carbohydrates and fat by $50 \%$ had been found to be associated not only with a prolonged lifespan and a markedly reduced incidence of breast cancer, but also with an increased circadian amplitude of the blood eosinophil rhythm [12]. Restriction in access time to food had predictable effects upon a number of circadian hormonal and metabolic rhythms in humans and rodents at several integration levels: core temperature, serum corticosterone, liver glycogen, corneal mitoses, chronotolerance of adriamycin and survival in a cool environment [152]. At two different ages, 2-day starvation of LOU rats was associated with an increase in urinary sodium, potassium and glucose excretion (in the young but not the older animals in the case of glucose excretion) and with an amplification of the circadian rhythm in these variables and also of urinary volume [153]. An increase in the circadian amplitude of plasma melatonin of rats after 48 hours of starvation was also documented by Zeman et al. [154], contributing to the earlier observations of the persistence during starvation of circadian rhythms in pituitary ACTH and corticosterone in the adrenal and in the circulation [39]. 
The amplitudes of circadian rhythms in rectal temperature, serum corticosterone and liver glycogen were all increased by meal feeding in either early light or early darkness [155]. The MESORs of corticosterone and glycogen were also increased by meal feeding at either stage of the lighting regimen. The circadian acrophases of temperature, corticosterone and glycogen were determined by the time of food presentation, regardless of its relation to the lighting regimen [155]. The interval between food presentation and the circadian acrophase of corneal mitotic index was greater when feeding was restricted to early light [155]. Mice fed in early light weighed more and exhibited more irregular circadian variation in temperature, corticosterone and mitotic index than did mice fed in early darkness [155].
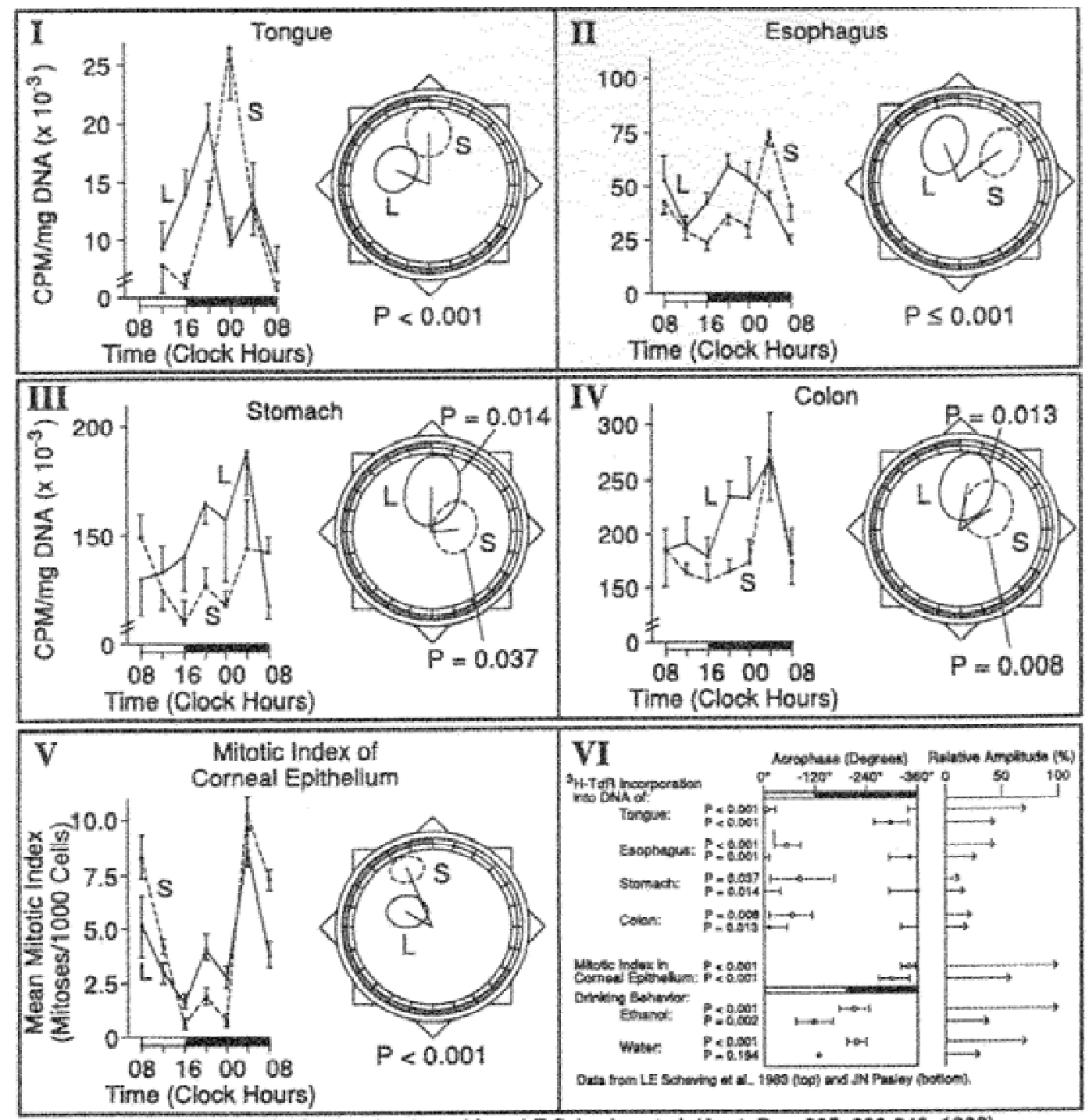

S = Sham-operated; $\mathrm{L}=\mathrm{SCN}$ lesioned; adapted from LE Scheving et al. (Anat. Rec. 205: 239-249, 1983). DAINKING BEHAVIOR

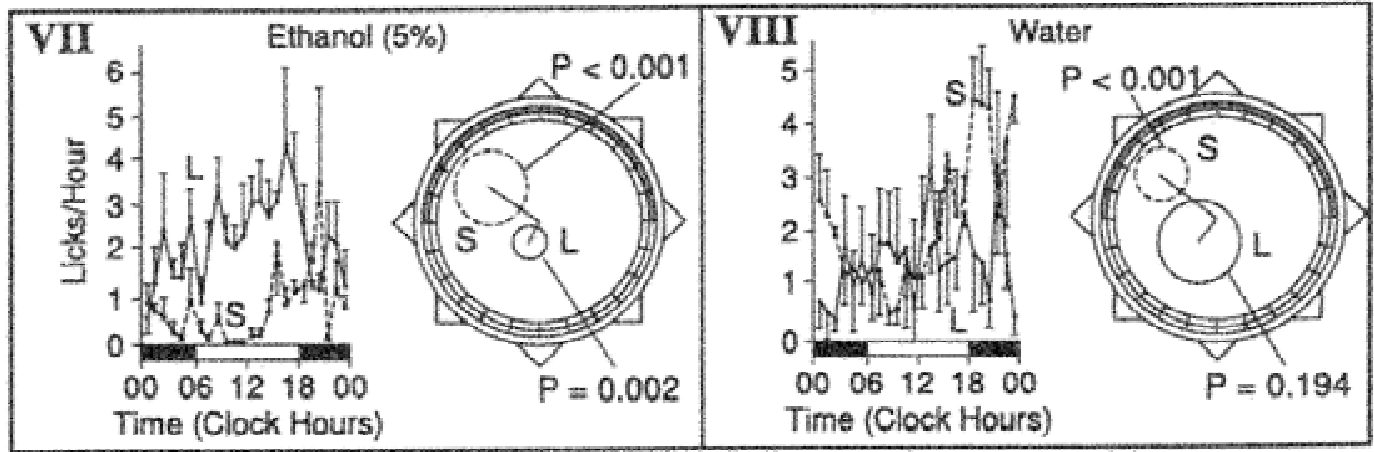

Fig. (28). Polar cosinor displays quantify a phase advance of rhythms after histologically validated bilateral SCN ablation in several tissues, with the exception of the stomach, which may respond to food directly rather than via the SCN. (C) Halberg (with permission). 
The postulate that a lower temperature brought about by calorie restriction may underlie, at least in part, its beneficial effect in retarding senescence and increasing longevity remains central to current investigations. This question was examined by Rikke et al. [156] who compared the temperature response of 28 different strains of singly-housed female mice fed $60 \%$ of their ad libitum intake. These authors report a highly statistically significant variation, ranging from 1.5 to $5.0^{\circ} \mathrm{C}$ among the different strains, representing a genealogically diverse sample of the classical inbred strains. This variation reportedly could not be accounted for by differences in loss of thermoregulation, ad libitum adiposity, sensitivity to hypothermia, motor activity, or absolute food intake [156].

Body temperature and fasting insulin were the two biomarkers of longevity found to be decreased by prolonged calorie restriction in humans [157]. This 6-month randomized controlled trial involved 48 overweight, nonobese healthy, sedentary men and women assigned to one of four groups consisting of weight maintenance diet, calorie restriction by $25 \%$ from reference stage, calorie restriction by $12.5 \%$ from reference stage with $12.5 \%$ increase in energy expenditure by structured exercise, and very low calorie diet to achieve $15 \%$ weight reduction [157].

According to a 2007 review [158], 20\% calorie restriction over 2 to 6 years in humans is associated with reduced body weight, blood pressure, blood cholesterol, and blood glucose, variables related to major killer diseases. The Okinawans, presumably the longest-lived people on earth, consume $40 \%$ fewer calories than the Americans and live 4 years longer [158].

The extension of lifespan by means of caloric restriction has been observed in a wide variety of organisms, ranging from yeast to mammals [159]. Reducing glucose in the growth medium of Saccharomyces cerevisiae reportedly extends both the replicative and chronological lifespans [159]. Yeast Sirtuins were apparently not required for the lifespan extension associated with caloric restriction [159]. By contrast, low temperature and high osmolarity additively extended the chronological lifespan when combined with caloric restriction [159]. Elevated respiration capacity was also observed to be an important determinant of longevity in this model [159].

Low body temperature has been reported to improve health and longevity independently of caloric restriction [160]. Carrillo and Flouris [160] present a model describing how caloric restriction and low body temperature increase lifespan synergistically and independently. Interestingly, these authors also consider the nascent notion that the rate of aging may be pre-programmed in response to environmental influences at critical stages of early development.

\section{PUTATIVE ROLE OF THE SUPRACHIASMATIC NUCLEI (SCN)}

Froy and Miskin [161] suggest that appropriately reset peripheral rhythms could constitute an important mediator of longevity in calorie-restricted animals. They note that the transgenic alphaMUPA mice that exhibit spontaneously reduced eating live longer as compared to their FVB/N wild- type controls, also have large-amplitude, appropriately reset circadian rhythms, notably in clock gene expression in the liver, feeding time and body temperature [162]. They posit that caloric restriction, and possibly also intermittent fasting (food available ad libitum every other day), can synchronize the circadian system in the SCN [163].

The critical role in circadian timing of the hypothalamus, by virtue of its anatomical location and physiological secretions, was theoretically anticipated on the precedent of its role in sex gland coordination [164]. Rhythmicity of some variables, however, persisted after a suprapontine brain ablation [165]. As seen in Fig. (28), circadian rhythms in the incorporation of tritiated thymidine into DNA of tongue, oesophagus, stomach, and colon, and in the mitotic index of corneal epithelium persist after lesioning of the suprachiasmatic nuclei (SCN). This is also the case for ethanol drinking behavior, albeit with a usual phase advance. Only in the case of water drinking was a circadian rhythm not detected after SCN lesioning [166]. Whereas the circadian amplitude is usually at least numerically reduced by the removal of the SCN, spontaneous circadian rhythms characterizing DNA synthesis and mitosis in the stomach and colon of mice are actually amplified [166, 167], Fig. (28). The effect of SCN lesioning upon the circadian amplitude of DNA labeling elsewhere in the gut is a smaller reduction in amplitude, as compared to that in other tissues $[166,167]$. The relative independence of the gut from the SCN, and perhaps a subtractive coupling of the stomach to the SCN, deserves further investigation, notably since the circadian amplitude of core temperature is statistically significantly increased in association with a unilateral SCN lesioning, whereas it is reduced in association with a bilateral SCN lesioning [167].

\section{CLOCK GENES}

A circadian rhythm can be demonstrated for several clock genes in peripheral tissues, including the liver and stomach, after 3 days in continuous darkness [168-171]. Period genes were shown to coordinate rhythmic changes in colonic motility [172]. Intra-colonic pressure changes and stool output in vivo, and colonic circular muscle contractility ex vivo were shown to be rhythmic with greatest activity at the start of night in nocturnal wild-type mice. By contrast, rhthmicity in these variables was absent in perlper 2 doubleknockout mice [172]. Rhythmicity also could not be detected in colonic circular muscle contractility of wild-type mice in the presence of $\mathrm{N} \omega$-nitro-L-arginine methyl ester and in nNOS knockout mice, suggesting that rhythms in colonic motility are coordinated by both clock genes and a nNOSmediated inhibitory process, and that the two mechanisms may be connected [172].

The effects of timed feeding and vagotomy on temporal clock gene expression in the gastrointestinal tract and SCN of C57BL/6J mice were examined using real-time polymerase chain reaction and Western blotting, while colonic clock gene localization was examined using immunohistochemistry [173]. Clock immunoreactivity was observed in the myenteric plexus and epithelial crypt cells. Clock genes were expressed rhythmically throughout the 
gastrointestinal tract [173]. Timed feeding shifted clock gene expression at the RNA and protein level but did not significantly shift clock gene expression in the SCN. Vagotomy did not alter gastric clock gene expression as compared to sham-treated controls [173]. The murine gastrointestinal tract thus contains functional clock genes, which are molecular core components of the circadian system. Day-time feeding in nocturnal rodents is a strong synchronizer of gastrointestinal clock genes, occurring independently of the SCN [173].

The effects of acute (1 week) and chronic (12 weeks) streptozotocin (STZ)-induced diabetes on period (per) genes in the stomach body, proximal and distal colon, liver, kidney and lung of C57BL/6J mice were assessed using real-time polymerase chain reaction. Rhythmicity in expression of per 2 and per 3 persisted in all organs, but was generally phase delayed within the gastrointestinal tract but not within the kidney or lung in STZ-injected mice as compared with vehicle-injected mice [174]. The phase delay was most pronounced for per 2 in the proximal colon at 12 weeks [174]. Food intake was rhythmic with a similar acrophase but a larger circadian amplitude for diabetic mice than for control mice [174]. Alterations in clock gene expression in a mouse model of diabetes are thus most pronounced in those organs that are intimately associated with food processing and metabolism.

Energy coordination and the circadian clock have also been linked at the molecular, physiological and behavioral levels by others [175]. Genetic mutation of the Clock gene, for instance, has been associated with the metabolic syndrome in mice [176]. Likewise, a high-fat diet reportedly affects circadian behavior and circadian patterns of metabolic gene expression [177]. Without citation to the extensive body of evidence accumulated by Franz Halberg and his associates worldwide, the fact that "the timing of food intake itself may play a significant role in weight gain" is being rediscovered [175]. Arble et al., [175] indeed show that nocturnal mice fed a high-fat diet only during the 12 hour light span gain more weight than mice fed only during the 12-hour dark span.

Recent human studies, as well, are in keeping with results accumulated during Franz Halberg's lifetime's work. In data from 499 participants in the Seasonal Variation of Blood Cholesterol Study, skipping breakfast was reportedly associated with an increased prevalence of obesity [178]. Moreover, night eating syndrome, characterized by a timedelayed pattern of eating relative to sleep, where most food is consumed in the evening and night, was reported to be positively associated with body mass index [179; cf. 180].

\section{CONCLUSION}

That meal timing has important effects on the body supports the proposition that optimal nutrition requires consideration of when food is consumed. Meal timing may have important implications regarding the ability to obtain "more for less" in a world of ever-increasing shortages. Meal timing can also serve as the basis for optimization of health, safety and productivity.

Meal timing can affect body weight, plasma concentrations of several hormones, body temperature, corneal mitoses, blood pressure and many other body functions in humans and many other forms of life [30]. It is wasteful to dismiss these effects as feeding phenomena. It is even short-sighted to deal with time structure as merely "another factor" like genetics that is usually controlled, when possible, but that one cannot (as yet) routinely manipulate [30]. Nutritionists can use the facts, methods and concepts of chronobiology pioneered by Franz Halberg [30].

His contributions, however, range far beyond the field of nutrition. One convincing example is that timing matters also for treatment. Franz doubled the 2-year disease-free survival time of patients with peri-oral cancers treated by radiotherapy timed in relation to marker rhythmometry [181, 182; cf. 183]. Major new directions in endeavors I could share with Franz concern how psychophysiology and pathology are affected by the cosmos, human mood in particular [184, 185], and how our environment near and far may affect a novel set of Vascular Variability Disorders, but these are other stories for other days.

\section{CONFLICT OF INTEREST}

Declared none.

\section{ACKNOWLEDGMENTS}

Special thanks are extended to Dr Walter Nelson who for most of his professional life worked very closely with Franz Halberg and who deserves enormous credit for bringing to fruition the longevity studies on rodents reported herein. His cogent comments and those of Dr Weihong Pan in reviewing this manuscript are gratefully acknowledged.

\section{REFERENCES}

[1] Atharva-Veda S. (written c. 3000-5000 BC). In: Lanman ChR, Ed. Whitney WD, Transl. Lanman Harvard Oriental Series, Delhi: Motilal Banarsidass 1984.

[2] Brillat-Savarin JA. Aphorisms 3 and 4. In: Taste physiology, or, Meditations on transcending gastronomy. Theoretical, historical, and up-to-date work dedicated to Parisian gastronomes. Paris: A. Soutelet Co. Vol. I, 1926.

[3] Virey JJ. Ephemerides of human life or research on daily revolution and periodicity of its phenomena in health and disease. Thesis. Paris: University of Paris 1814; p.39.

[4] Halberg F, Cornelissen G, Katinas G, et al. Transdisciplinary unifying implications of circadian findings in the 1950s. J Circadian Rhythms 2003; 1: 61.

[5] Dalton AJ, Selye H. Blood picture during alarm reaction. Folia Hematologica 1939; 62: 397-407.

[6] Best WR, Muehrcke RC, Kark RM. Clinical and statistical evaluation of four-hour eosinophil response tests. J Lab Clin Med 1951; 38: 790-1.

[7] Best WR, Muehrcke RC, Kark RM. Studies on adrenocortical eosinopenia: a clinical and statistical evaluation of four-hour eosinophil response test. J Clin Invest 1952; 31(7): 733-42.

[8] Best WR, Kark RM, Muehrcke RC, Samter M. Clinical value of eosinophil counts and eosinophil response tests. JAMA 1953; 151(9): 702-6.

[9] Halberg F, Visscher MB. Regular diurnal physiological variation in eosinophil levels in five stocks of mice. Proc Soc exp Biol (NY) 1950; 75: 846-7.

[10] Halberg F, Bittner JJ, Visscher MB. Tail blood eosinophil levels in several inbred strains of mice under standard conditions. Blood 1951; 6: 832-7.

[11] Halberg F, Visscher MB, Bittner JJ. Eosinophil rhythm in mice: Range of occurrence; effects of illumination, feeding and adrenalectomy. Amer J Physiol 1953; 174: 109-22. 
[12] Halberg F, Visscher MB. A difference between the effects of dietary calorie restriction on the estrous cycle and on the 24hour adrenal cortical cycle in rodents. Endocrinology 1952; 51: 329-35.

[13] Halberg F, Haus E, Nelson W, Sothern R. Chronopharmacology, chronodietetics and eventually clinical chronotherapy. Nova Acta leopold 1977; 46: 307-66.

[14] Halberg F, Kabat HF, Klein P. Chronopharmacology: a therapeutic frontier. Am J Hosp Pharmacy 1980; 37: 101-6.

[15] Halberg F, Cornelissen G, Schwartzkopff O. Introduction: Time, diagnostics, and therapeutics -- beyond circadian marker rhythmguided treatment. In: Youan BC, Ed. Chronopharmaceutics: Science and technology for biological rhythm-guided therapy and prevention of diseases. Hoboken, NJ: Wiley 2009; pp. xvii-xxxii.

[16] Halberg F, Cornelissen G, Schwartzkopff O. Chapter 10: Implications and applications of circadian susceptibility rhythms: chronomics and anesthesia. In: Youan BC, Ed. Chronopharmaceutics: Science and technology for biological rhythm-guided therapy and prevention of diseases. Hoboken, NJ: Wiley 2009; pp. 217-55.

[17] Cornelissen G, Halberg F. Chapter 11: Treatment with open eyes: markers-guided chronotheranostics. In: Youan BC, Ed. Chronopharmaceutics: Science and technology for biological rhythm-guided therapy and prevention of diseases. Hoboken, NJ: Wiley 2009; pp. 257-323.

[18] Halberg F. Chronobiology and nutrition. Contemp Nutr 19838 (9): 2 .

[19] Halberg J, Halberg E, Halberg F. Nonobese mammals pair-fed or on free-choice diets may be "what they eat" but body weight and internal circadian timing are rhythmometrically specifiable functions of "when they eat". Proc. X Int. Cong. Nutrition, Kyoto, Japan, abstract \#211, 1975; p. 16.

[20] Halberg F, Sullivan B. Meal schedules and their interaction with the body's schedules. Chronobiologia 1976; 3: 75-6.

[21] Halberg F, Haus E, Cornelissen G. From biologic rhythms to chronomes relevant for nutrition. In: Marriott BM, Ed. Not eating enough: overcoming underconsumption of military operational rations. Washington DC: National Academy Press 1995; pp. 361-72.

[22] Forsgren E. Zur Kenntnis der Histologie der Leberzellen und der Gallensekretion. Anat Anz 1918; 51: 309-14.

[23] Forsgren E. On the relationship between the formation of bile and glycogen in the liver of the rabbit. Scand Arch Physiol 1928; 53: $137-51$.

[24] Ågren G, Wilander O, Jorpes E. Cyclic changes in the glycogen content of the liver and the muscles of rats and mice. Their bearing upon the sensitivity of the animals to insulin and their influence on the urinary output of nitrogen. Biochem J 1931: 25: 777-85.

[25] Halberg F. Physiologic 24-hour periodicity; general and procedural considerations with reference to the adrenal cycle. Z Vitamin-, Hormon-u Fermentforsch 1959; 10: 225-96.

[26] Ågren G. Cyclic changes in liver glycogen of rats after adrenalectomy. Biochem Z 1935; 281: 367-9.

[27] Sollberger A. Diurnal changes in biological variability. Acta Anat 1955; 23: 259-87.

[28] Chossat C. Recherches expérimentales sur l'inanition. Mém Acad Sci Inst Fr 1843; 8: 438.

[29] Higgins GM, Berkson J, Flock E. The diurnal cycle in the liver. 1. Periodicity of the cycle with analysis of chemical constituents involved. Am J Physiol 1932; 102: 673-82; 2. Food, a factor in its determination. 1933; 105: 177-86.

[30] Halberg F. Some aspects of the chronobiology of nutrition: more work is needed on "when to eat". J Nutr 1989; 119: 333-43.

[31] Haus E, Halberg F. Persisting circadian rhythm in hepatic glycogen of mice during inanition and dehydration. Experientia (Basel) 1966; 22: 113-4

[32] Graeber RC, Gatty R, Halberg F, Levine H. Human eating behavior: preferences, consumption patterns and biorhythms. Technical Reports NATICK/TR-78/022 U.S. Army .1978; p. 287.

[33] Bornstein A, Volker H. Uber die Schwankungen des Grundumsatzes. Z Ges Exp Med 1926; 53: 439-50.

[34] Apfelbaum M, Reinberg A, Lacatis D, Abulker, Bostsarron J, Riou F. Rythme circadian de la consummation d'oxygène et du quotient respiratoire de femmes adultes jeunes en alimentation spontanée et après restriction calorique. Europ J Clin Res 1971; 16: 135-43.

[35] Apfelbaum M, Bishop JS, Cressey D, et al. Human or murine endocrine and metabolic rhythms after changes in meal timing with or without a fixed activity schedule. Proc. 56th Mtg. Endocrine Society, Abstract \#308, 1974.

[36] Heusner A. Analysis of the 24-hour variation of energy metabolism in the white rat. D.Sc. Thesis. France: University of Strasbourg 1963.

[37] Bare J. Hunger, deprivation and the day-night cycle. J Comp Physiol Psychol 1959; 52: 129-31.

[38] Haus E, Hanton EM, Halberg F. 24-hour susceptibility rhythm to ethanol in fully-fed, starved and thirsted mice and the lighting regimen. Physiologist 1959; 2: 54.

[39] Halberg F, Galicich F, Ungar F, French LA. Circadian rhythmic pituitary adrenocorticotropic activity, rectal temperature and pinnal mitosis of starving, dehydrated C mice. Proc Soc exp Biol (NY) 1965; 118: 414-9.

[40] Galicich JH, Halberg F, French LA. Circadian adrenal cycle in C mice kept without food and water for a day and a half. Nature (Lond.) 1963; 197: 811-3.

[41] Scheving LE, Nelson W, Haus E, et al. Nutrition, metabolism and prominent circadian rhythms in plasma cortisol of men on an equidistant isocaloric diet as well as during food deprivation. Proc. 55th Ann. Mtg. Endocrine Society. Endocrinology 1973; 92(Suppl 429): A-263.

[42] Reinberg A. Chronobiology and nutrition. Chronobiologia 1974; 1: 22-7.

[43] Reinberg A, Halberg F, Ghata J, et al. Rythme circadien de diverses fonctions physiologiques de l'homme adulte sain, actif et au repos (pouls, pression artérielle, excrétions urinaires des 17OHCS, des catécholamines et du potassium). Test du cosinor. J Physiol (Paris) 1969; 61(Suppl. 2): 383.

[44] Goetz FC, Bishop J, Halberg F, et al. Timing of single daily meal influences relations among human circadian rhythms in urinary cyclic AMP and hemic glucagon, insulin and iron. Experientia (Basel) 1976; 32: 1081-4.

[45] Halberg F. Implications of biologic rhythms for clinical practice. Hosp Pract 1977; 12: 139-49.

[46] Halberg F, Halberg E, Carandente F. Chronobiology and metabolism in the broader context of timely intervention and timed treatment. In: Lindenlaub E, Ed. Diabetes research today, meeting of the Minkowski Prize Winners, Symposia Medica Hoechst 12 (Capri). Stuttgart/New York: F.K. Schattauer Verlag 1976; pp. 45-95.

[47] Reinberg A. Biological rhythms and energy balance in man. In: Apfelbaum M, Ed. Energy balance in man. Paris: Masson 1973; pp. 285-95.

[48] Caviezel F, Cattaneo AG, Matonti S, Vigano W, Pappalettera AE, Pozza G. Single daily meal treatment in obesity. In: Enzi G, Crepaldi G, Pozza G, Renold AE, Eds. Serono Symp. \#28. Obesity: Pathogenesis and Treatment. London/New York: Academic Press 1981; pp. 105-15.

[49] Capani F, Carfagnini A, Consoli F, et al. Chronobiological aspects of energy expenditure in obesity. In: Enzi G, Crepaldi G, Pozza G, Renold AE, Eds. Serono Symp. \#28. Obesity: Pathogenesis and treatment. London/New York: Academic Press 1981; pp. 87-103.

[50] Bowen A, Reeves R. Diurnal variations in glucose tolerance. Arch Int Med 1967; 119: 261-4.

[51] Gagliardino JJ, Hernandez RE. Circadian variation of the serum glucose and immunoreactive insulin levels. Endocrinology 1971; 88: 1529.

[52] Lakatua DJ, Haus E, Gold EM, Halberg F. Circadian rhythm of ACTH and growth hormone in human blood. Time relations to adrenocortical blood and urinary rhythms. In: Scheving LE, Halberg F, Pauly JE, Eds. Chronobiology, Proc. Int. Soc. For the Study of Biological Rhythms, Little Rock, Ark. Tokyo: Igaku Shoin Ltd. 1974; pp. 123-129.

[53] Rapoport M, Beisel W. Circadian periodicity of tryptophan metabolism. J Clin Invest 1968; 47: 934-9.

[54] Wurtman R. Diurnal rhythms in mammalian protein metabolism. Mamm Protein Metab 1970; 4: 445-79. 
[55] Potter V, Gebert R, Pilot H, et al. Systematic oscillations in metabolic activity in rat liver and in hepatomas. I. Morris hepatoma No. 7793. Cancer Res 1966; 26: 1547-60.

[56] Gagliardino JJ, Pessaq MT. Diurnal variations in the action of insulin on muscle glycogen synthesis. J Endocrinol 1974; 61: 171-7.

[57] Bünning E. The physiological hour. Berlin: Springer 1958.

[58] Scheving LE. The circadian influence of epidermal growth factor (EGF), insulin and glucagon on cell proliferation in the digestive tract. In: Chronobiology and the digestive system. US: NIH Publ. \#84-857, 1984; pp. 41-68.

[59] Scheving LE, Burns ER, Pauly JE, Tsai TH. Circadian variation in cell division of the mouse alimentary tract, bone marrow and corneal epithelium. Anat Rec 1978; 191: 479-85.

[60] Hamar N. Daily changes in glucose uptake in the small intestine. Arch Ges Physiol 1940; 244: 164-70.

[61] Chronobiology and the Digestive System. U.S. Department of Health and Human Services: NIH Publ. \#84-857, 1984; p. 116.

[62] Halberg F, Cornélissen G, Shemerovsky C. From Pavlov's time coding and conditioned reflexes to a chronophysiology of human nutrition. Rom J Physiol 1995; 32: 97-106.

[63] Halberg F, Moore JG, Gibinski K, Szabo S. Further chronobiologic steps in gastroenterology. Chronobiologia 1983; 10: 409-23.

[64] Markiewicz A. Chronobiological aspects of jejunum function in humans. Chronobiol Int 1992; 9: 453-61.

[65] Markiewicz A, Kaminski M, Tarquini B, Halberg F. Circadian rhythm of enzymatic activity in human jejunum. Int $\mathbf{J}$ Chronobiol 1981; 7: 282.

[66] Markiewicz A, Koszyk T, Reising J. Seasonal variations of inflammation and ulcer incidence as assessed by upper digestive tract endoscopy. Chronobiologia 1986; 13: 117-21.

[67] Moore JG, Englert E Jr. Circadian rhythm of gastric acid secretion in man. Nature 1970; 226: 1261-2.

[68] Moore JG, Halberg F. Circadian rhythm of gastric acid secretion in active duodenal ulcer: chronobiological statistical characteristics and comparison of acid secretory and plasma gastrin patterns with healthy subjects and post-vagotomy and pyloroplasty patients. Chronobiol Int 1987; 4: 101-10.

[69] Tarquini B. Physiopathology of peptic ulcer: a new view. Rass Med sper 1980; 27: 279-302.

[70] Tarquini B, Rosati I, Serantoni C. Circadian studies on gastric mitotic index in patients with duodenal ulcer and in control group. Chir Gastroent 1977; 11: 367-71.

[71] Tarquini B, Lombardi P, Pernice LM, Andreoli F. Gastric continuous $\mathrm{pH}$ monitoring: a new apparatus in chronobiological research. In: Scheving LE, Halberg F, Ehret CF, Eds. Chronobiotechnology and chronobiological engineering. dordrecht, The Netherlands: Martinus Nijhoff 1987; pp. 390-392.

[72] Gibinski K, Nowak A, Rybicka J, Czamecka K. An endoscopic study on the natural history of gastroduodenal ulcer disease. Mater med pol 1979; 11: 265-9.

[73] Malinovskaya NK, Komarov FI, Rapoport SI, Voznesenskaya LA, Wetterberg L. Melatonin production in patients with duodenal ulcer. Neuroendocrinol Lett 2001; 22: 109-17.

[74] Thaela MJ, Jensen MS, Cornelissen G, et al. Circadian and ultradian variation in pancreatic secretion of meal-fed pigs after weaning. J Animal Sci 1998; 76(4): 1131-9.

[75] Zabielski R, Onaga T, Mineo H, Kato S. Periodic fluctuations in pancreatic secretion and duodenal motility investigated in neonatal calves. Exp Physiol 1993; 78: 675-84.

[76] Zabielski R, Terui Y, Onaga T, Mineo H, Kato S. Plasma secretin fluctuates in phase with periodic pancreatic secretion and the duodenal migrating myoelectric complex in calves. Res Vet Sci 1994; 56: 332-7.

[77] Bubenik GA, Pang SF, Cockshut JR, et al. Circadian variation of portal, arterial and venous blood levels of melatonin in pigs and its relationship to food intake and sleep. J Pineal Res 2000; 28: 9-15.

[78] Cornelissen G, Kanabrocki E, Halberg J, Halberg F. Toward the chronobiology and chronomics of the intestine. In: Zabielski R, Gregory PC, Weström B, Eds. Biology of the intestine in growing animals. Amsterdam: Elsevier NV 2002; pp. 751-804.

[79] Ader R. Gastric erosions in the rat: effects of immobilization at different points in the activity cycle. Science 1964; 145: 406-7.

[80] Brown SD, Finger FW. Circadian variation of ulcer susceptibility in the rat. In: Scheving LE, Halberg F, Pauly JE, Eds.
Chronobiology: Proc. Int. Soc. for the study of biological rhythms, Little Rock, Ark. Stuttgart: Georg Thieme Publishers/Tokyo: Igaku Shoin Ltd 1974; pp. 316-9.

[81] Carandente F, Halberg E, Dubey DP, Beard K, Klein P, Halberg F Chronobiology and sex as codeterminants of gastric ulcerogenesis in loaded rats of two inbred strains. In: Halberg F, Ed. Proc. XII Int. Conf. International Society for Chronobiology, Washington, D.C. Milan: Il Ponte 1977; pp. 157-66.

[82] Trout DL, King SA, Bernstein PA, Halberg F, Cornelissen G. Circadian variation in the gastric-emptying response to eating in rats previously fed once or twice daily. Chronobiology Int 1991; 8: 14-24.

[83] Damiola F, Minh NL, Preitner N, Kornmann B, Fleury-Olela F, Schibler U. Restricted feeding uncouples circadian oscillators in peripheral tissues from the central pacemaker in the suprachiasmatic nucleus. Gene Develop 2000; 14: 2950-61.

[84] Stokkan KA, Yamazaki S, Tei H, Sakaki Y, Menaker M. Entrainment of the circadian clock in the liver by feeding. Science 2001; 291: 490-2.

[85] Halberg F, Visscher MB. Effect of light and of availability of food upon the 24-hour rhythm in number of circulating eosinophils in mice. Am J Physiol 1952; 171: 732.

[86] Pauly JE, Burns ER, Halberg F, Tsai TS, Betterton HO, Scheving LE. Meal timing dominates lighting regimen as a synchronizer of the eosinophil rhythm in mice. Acta anat (Basel) 1975; 93: 60-8.

[87] Halberg F, Cornelissen G, Haus E. Timing nutrition, both for weight gain and weight loss. Chronobiologia 1994; 21: 356-7.

[88] Scheving LE, Burns ER, Pauly JE, Tsai S, Halberg F. Meal scheduling, cellular rhythms and the chronotherapy of cancer. Chronobiologia 1976; 3: 80.

[89] Halberg E, Nelson W, Scheving LE, et al. Interactions of mealscheduling, lighting and housing influence the timing of circadian rhythms to a different extent at different levels of murine organization. Int J Chronobiol 1973; 1: 327-8.

[90] Scheving LE, Pauly JE, Burns ER, Halberg F, Tsai S, Betterton HO. Lighting regimen dominates interacting meal schedules and synchronizes mitotic rhythm in mouse corneal epithelium. Anat Rec 1974; 180: 47-52.

[91] Potter VR, Gebert RA, Pitot HC. Enzyme levels in rats adapted to 36-hour fasting. Adv Enzyme Res 1966; 4: 247-65.

[92] Walker RP, Potter VR. Diurnal rhythms of hepatic enzymes from rats adapted to controlled feeding schedules. In: Scheving LE, Halberg F, Pauly JE, Eds. Chronobiology, Proc Int Soc for the study of biological rhythms, Little Rock, Ark. Tokyo: Igaku Shoin Ltd. 1974; pp. 17-22.

[93] Cohn C, Joseph D, Larin F, Shoemaker WJ, Wurtman RJ. Influence of feeding habits and adrenal cortex on diurnal rhythm of hepatic tyrosine transaminase activity. Proc Soc Exp Biol Med 1970; 133: 460-2.

[94] Fuller RW. Daily variation in liver tryptophan, tryptophan pyrrolase and tyrosine transaminase in rats fed ad libitum or single daily meals. Proc Soc Exp Biol Med 1970; 133: 620-2.

[95] Nelson W, Nichols G, Halberg F, Kottke G. Interacting effects of lighting LD (12:12) and restricted feeding $4 \mathrm{hr} / 24 \mathrm{hr}$ on circadian temperature rhythm of mice. Int J Chronobiol 1973; 1: 347.

[96] Halberg E, Nelson W, Scheving LE, et al. Interactions of mealscheduling, lighting and housing influence the timing of circadian rhythms to a different extent at different levels of murine organization. Int J Chronobiol 1973; 1: 327-8.

[97] Mayersbach Hv, Muller O, Philippens E, Scheving LE, Steinbach G. Effect of restricted feeding schedules on various parameters of blood serum and liver of rats. Int J Chronobiol 1973; 4: 342-3.

[98] Pauly JE, Burns ER, Betterton H, Tsai H, Halberg F, Scheving LE. Effect of restricted feeding schedules on blood eosinophil levels and mitotic activity as well as other parameters in mice. Int $\mathbf{J}$ Chronobiol 1973; 1: 348-9.

[99] Halberg F, Bobb JRR, Visscher MB. Absolute numbers of circulating eosinophil blood cells in dogs starved for three days. Fed Proc 1950; 9: 54.

[100] Stupfel M, Halberg E, Halberg F. L'accès alimentaire périodique des rats groupés surmonte l'alternance lumière-obscurité comme synchroniseur du rythme circadien d'émission de gaz carbonique. CR Acad Sci (Paris) 1973; 277: 873-6. 
[101] Katinas GS, Cornelissen G, Halberg F. Timing availability of food alters functional circadian differences within intracellular morphology of rat enterocytes. Proceedings, International Conference on the Frontiers of Biomedical Science: Chronobiology; 2006 Sept 24-26; Chengdu, China 2006; pp. 96-100.

[102] Meis PJ, Hulcher FH, Rose JR, Halberg J, Halberg F. Circadian meal schedule rhythmometry on plasma triglycerides of non-human primates. Chronobiologia 1979; 6: 131-2.

[103] Meis PJ, Hulcher FH, Rose JR, Halberg J, Halberg F. Individualized circadian alimentary meta (meal schedule-shift)rhythmometry on surface temperature of nonhuman primates. Abstracts of papers, Minn. Acad. Sci., 47th Annual Spring Meeting; 1979 May 4-5; University of Minnesota, Morris 1979; pp. 18-19.

[104] Meis PJ, Hulcher FH, Rose JC, Halberg J, Halberg F. Meal timing alters circadian rhythm of skin surface temperature in non-human primates. Int J Chronobiol 1980; 7: 65-76.

[105] Meis PJ, Rose JC, Halberg F, Halberg J, Hulcher FH. Comparative effects of meal timing on circadian rhythms of plasma insulin and skin surface temperature in non-human primates. Chronobiologia 1983; 10: 13-9.

[106] Lakatua DJ, Halberg F, Haus E, et al. Timing of single daily meals serves to manipulate relations among human circadian plasma growth hormone, cortisol, insulin and cardiovascular rhythms. Endocrinology 1976; 98, Supplement: Proc. 58th Mtg. Endocrine Soc., abstract $285,456$.

[107] Halberg F. Implications of biologic rhythms for clinical practice. Hosp Pract 1977; 12: 139-49.

[108] Levine H, Lakatua D, Haus E, Halberg E, Halberg F. Interpersonal and intervariable differences in meal timing effects upon circadian rhythms in pulse, blood pressure and blood hormones of presumably healthy volunteers. Physiologist 1975; 18: 289.

[109] Goetz FC, Bishop J, Halberg F, et al. Timing of single daily meal influences relations among human circadian rhythms in urinary cyclic AMP and hemic glucagon, insulin and iron. Experientia (Basel) 1976; 32: 1081-4.

[110] Nelson W, Cadotte L, Halberg F. Circadian timing of single daily "meal" affects survival of mice. Proc Soc exp Biol (NY) 1973; 144: 766-9.

[111] Nelson W, Halberg F. Meal-timing, circadian rhythms and lifespan of mice. J Nutr 1986; 116: 2244-53.

[112] Nelson W, Fundakowski R, Baer J, Cadotte L, Halberg F. An apparatus for automatically timing access of mice to food. Lab Anim Sci 1982; 31: 66-9.

[113] Halberg F. On the timing of meals and drugs and the underlying physiologic mechanisms. Indian Soc Clin Exp Hypnos Newsletters 1978; 6: 1-12.

[114] Halberg F, Nelson W, Lakatua D, Cadotte L, Haus E. Circadian amplitude increase associated with caloric restriction of mice by single daily meal reduced by "pattern-feeding". Notiziario SIBioC 1982; 6: 250.

[115] Halberg F, Nelson W, Lakatua D, Cadotte L, Haus E. Circadian amplitude increase associated with caloric restriction of mice by single daily meal reduced by "pattern-feeding". In: Haus E, Halberg F, Eds. Chronobiology 1982-1983. Basel: S. Karger 1984; pp. 490-2.

[116] Halberg F, Nelson W, Lakatua D, Cadotte L, Haus E. Circadian amplitude increase associated with caloric restriction by single daily meal reduced by "pattern-feeding" in mice. Int J Chronobiol 1981; 7: 251.

[117] Nelson W, Halberg F. Schedule-shifts, circadian rhythms and lifespan of freely-feeding and meal-fed mice. Physiol Behav 1986; 38: 781-8.

[118] Halberg F, Sanchez S, Nelson W. Rhythm scrambling and tumorigenesis in $\mathrm{CD}_{2} \mathrm{~F}_{1}$ mice. In: Tarquini B, Vergassola R, Eds. III Int. Symposium, social diseases and chronobiology, Florence, Nov. 29, 1986. Rome: Istituto Italiano di Medicina Sociale 1986; pp. 59-61.

[119] Halberg F, Cornelissen G, Halberg E, et al. Toward chronobiologic optimization of nutrition for cancer treatment and broad disease prevention. In: Roche AF, Ed. The role of nutrients in cancer treatment, Report of the 9th Ross Conference on Medical Research. Columbus, OH: Ross Laboratories 1991; pp. 2-9.

[120] Halberg F, Haus E, Cardoso SS, et al. Toward a chronotherapy of neoplasia: Tolerance of treatment depends upon host rhythms. Experientia (Basel) 1973; 29: 909-34.
[121] Nelson W, Halberg F, Scheving L. Meal timing as an adjuvant of experimental chronotherapy: circadian rhythm in tolerance of adriamycin by mice on a 24-hour cyclic lighting regimen-the usually dominant synchronizer routine-is shifted by restricting feeding to early light span. XI Int. Cancer Congress, Florence, Italy, 1974; 3: 417.

[122] Halberg F, Nelson W. Chronotherapy of immunocytoma made feasible by meal timing. Proc AACR 1976; 19: 190.

[123] Nelson W, Halberg F, Zinneman H, Haus E, Scheving L, Bazin H. Survival of immunocytoma-bearing rats affected by meal-feeding and timing of adriamycin treatment. In: Halberg F, Ed. Proc. XII Int. Conf. International Society for Chronobiology, Washington, D.C., 1977. Milan: Il Ponte 1977; pp. 443-7.

[124] Nelson W, Halberg F, Zinneman H, Haus E, Scheving L, Bazin H. Survival of immunocytoma-bearing rats affected by meal-feeding and timing of adriamycin treatment. Chronobiologia 1975; 2(Suppl. 1): 51.

[125] Yunis E, Shankaraiah K, Watson ALM, Derr LK, Halberg F. Longevity and delayed mammary carcinogenesis compatible with competing (24-hour) lighting and (48-hour) feeding schedules: internal circadian-circaduodian murine desynchronization. Int $\mathrm{J}$ Chronobiol 1981; 7: 347.

[126] Shankaraiah K, Halberg F, Yunis E, Watson ALM. Alternate-day feeding alters the circadian system, reduces breast cancer incidence and prolongs life. In: Halberg F, Reale L, Tarquini B, Eds. Proc. 2nd Int. Conf. Medico-Social Aspects of Chronobiology, Florence, Oct. 2, 1984, Rome: Istituto Italiano di Medicina Sociale 1986; pp. 633-48.

[127] Nelson W, Halberg F, Shankaraiah K. Rhythm scrambling: good, bad or indifferent? Chronobiologia 1987; 14: 291-5.

[128] Yunis EJ, Watson ALM, Shankaraiah K, Halberg F. Dietary restriction and aging. Notiziario SIBioC 1982; 6: 527.

[129] Halberg F, Cornelissen G, Wang ZR, et al. Chronomics: circadian and circaseptan timing of radiotherapy, drugs, calories, perhaps nutriceuticals and beyond. J Exp Therapeutics Oncol 2003; 3: 223-60.

[130] Ranjana S, Rajesh SK, Mahdi AA, et al. Circadian periodicity of plasma lipid peroxides and other anti-oxidants as putative markers in gynecological malignancies. in vivo 2003; 17: 593-600.

[131] Lee JY, Gillum RF, Cornelissen G, Koga Y, Halberg F. Individualized assessment of circadian rhythm characteristics of human blood pressure and pulse after moderate salt and weight restriction. In: Takahashi R, Halberg F, Walker C, Eds. Toward Chronopharmacology, Proc. 8th IUPHAR Cong. and Sat. Symposia, Nagasaki, July 27-28, 1981. Oxford/New York: Pergamon Press 1982; pp. 375-90.

[132] Halberg F, Cornelissen G. I: Rhythms and blood pressure. Ann Ist Super Sanità 1993; 29: 647-55.

[133] Cornelissen G, Kawasaki T, Uezono K, Delea C, Halberg F. II: Blood pressure rhythms and salt. Ann Ist Super Sanità 1993; 29: 667-77.

[134] Kawasaki T, Delea CS, Bartter FC, Smith H. The effect of highsodium and low-sodium intakes on blood pressure and other related variables in human subjects with idiopathic hypertension. Am J Med 1978; 64: 193-8.

[135] Bittle CC, Molina DJ, Bartter FC. Salt sensitivity in essential hypertension as determined by the cosinor method. Hypertension 1985; 7: 989-94.

[136] Itoh K, Kawasaki T, Cugini P. Effects of timing of salt intake to 24-hour blood pressure and its circadian rhythm. Ann NY Acad Sci 1996; 783: 324-5.

[137] Lim GB. Hypertension: salt restriction might lower blood pressure, but are there any beneficial effects on mortality? Nat Rev Cardiol 2011; 8: 479

[138] Cugini P, Lucia P, Murano G, et al. Chronobiologic effects on urinary aldosterone and related variables with a medium-term moderate reduction in salt and calorie intake. Alim Nutr Metab 1985; 6: 109-15.

[139] Cugini P, Murano G, Lucia P, et al. Effects of a mild and prolonged restriction in sodium or food intake on the circadian rhythm of aldosterone and related variables. Chronobiology Int 1987; 4: 245-50

[140] Rosen G, Johnson L, Halberg F, Sargent F II. Free-running individualized circannual rhythms in human infants' weight gain 
and carbohydrate, fat and protein intake. Chronobiologia 1976; 3 : 76-7.

[141] Carandente F, Halberg E, Beard K, et al. Circadian state as well as sex determine gastric ulcerogenesis in spontaneously mesorhypertensive rats. Chronobiologia 1976; 3: 78-9.

[142] Hirsch E, Halberg E, Halberg F, et al. Body weight change during 1 week on a single daily 2000-calorie meal consumed as breakfast (B) or dinner (D). Chronobiologia 1975; 2(Suppl. 1): 31-2.

[143] Jacobs H, Thompson M, Halberg E, et al. Relative body weight loss on limited free-choice meal consumed as breakfast rather than dinner. Chronobiologia 1975; 2(Suppl. 1): 33.

[144] Levine H, Halberg E, Halberg F, et al. Changes in internal timing of heart rate, diastolic blood pressure and certain aspects of physical and mental performance in presumably healthy subjects on different meal schedules. In: Halberg F, Ed. Proc. XII Int. Conf. International Society for Chronobiology, Washington, D.C., 1977. Milan: Il Ponte 1977; pp. 139-48.

[145] Sundararaj BI, Nath P, Halberg F. Circadian meal timing in relation to lighting schedule optimizes catfish body weight gain. J Nutr 1982; 12: 1085-97.

[146] Bazin H, Apfelbaum M, Assan R, et al. Redistributing proportions of food at conventional meal times reschedules differentially hormones and substrates involved in energy metabolism. Chronobiologia 1978; 5: 203.

[147] Bazin R, Apfelbaum M, Assan R, et al. Circadian rhythmic energy metabolism modified by within-day food redistribution: big breakfast versus big dinner. In: Reinberg A, Halberg F, Eds. Chronopharmacology, Proc. Satellite Symp. 7th Int. Cong. Pharmacol., Paris 1978. Oxford/New York: Pergamon Press 1979; pp. 303-10.

[148] Bazin H, Apfelbaum M, Assan R, Halberg F, de Gasquet P. Timing of meals manipulates amplitude and acrophase of circadian rhythms in human plasma insulin. Chronobiologia 1978; 5: $203-4$

[149] Uezono K, Kawasaki T, Sasaki H, et al. Circadian biological characteristics after shifting sleep and meal times. MEFA 8th International Fair of Medical Technology and Pharmacy; 2000 Nov 7-10; Brno, Czech Republic 2000.

[150] Uezono K, Kawasaki T, Sasaki H, et al. Circadian biological characteristics after shifting sleep and meal times. Scripta medica (Brno) 2002; 75: 145-50.

[151] Nelson W. Food restriction, circadian disorder and longevity of rats and mice. J Nutr 1988; 118: 284-9.

[152] Halberg F, Gehrke CW, Zinneman H, et al. Circadian rhythmic polyamine excretion by rats with immunocytoma. Physiologist 1976; 19: 215

[153] Anderson GE, Halberg F, Goetz FC, Haus E, Scheving LE, Bazin H. Circadian murine urinary volume, glucose, sodium and potassium characteristics manipulated by starvation in young adulthood and maturity. Chronobiologia 1979; 6: 73-4.

[154] Zeman M, Stebelova K, Cornelissen G, et al. Extension of Chossat phenomena to rat plasma melatonin: increase in circadian amplitude during starvation. Noninvasive Methods in Cardiology; 2005 Sept 14; Brno, Czech Republic 2005; p. 23.

[155] Nelson W, Scheving L, Halberg F. Circadian rhythms in mice fed a single daily meal at different stages of lighting regimen. J Nutr 1975; 105: 171-84.

[156] Rikke BA, Yerg JE $3^{\text {rd }}$, Battaglia ME, Nagy TR, Allison DB, Johnson TE. Strain variation in the response of body temperature to dietary restriction. Mech Ageing Dev 2003; 124(5): 663-78.

[157] Heilbronn LK, de Jonge L, Frisard MI, et al. Effect of 6-month calorie restriction on biomarkers of longevity, metabolic adaptation, and oxidative stress in overweight individuals: a randomized controlled trial. JAMA 2006; 295(13): 1539-48.

[158] Everitt AV, Le Couteur DG. Life extension by calorie restriction in humans. Ann N Y Acad Sci 2007; 1114: 428-33.

[159] Smith DL, McClure JM, Matecic M, Smith JS. Calorie restriction extends the chronological lifespan of Saccharomyces cerevisiae independently of the Sirtuins. Aging Cell 2007; 6(5): 649-62.

[160] Carrillo AE, Flouris AD. Caloric restriction and longevity: effects of reduced body temperature. Ageing Res Rev 2011; 10(1): 153-62.

[161] Froy O, Miskin R. The interrelations among feeding, circadian rhythms and ageing. Prog Neurobiol 2007; 82(3): 142-50.
[162] Froy O, Chapnik N, Miskin R. Relationship Between Calorie Restriction and the Biological Clock: Lessons from Long-Lived Transgenic Mice. Rejuv Res 2008; 11(2): 467-71.

[163] Froy O, Miskin R. Effect of feeding regimens on circadian rhythms: implications for aging and longevity. Aging 2010; 2(1): 7-27.

[164] Halberg F, Halberg E, Barnum CP, Bittner JJ. Physiologic 24-hour periodicity in human beings and mice, the lighting regimen and daily routine. In: Withrow $\mathrm{RB}, \mathrm{Ed}$. Photoperiodism and related phenomena in plants and animals. Ed. Publ. No. 55. Washington DC: AAAS 1959; pp. 803-78.

[165] Galicich JH, Halberg F, French LA, Ungar F. Effect of cerebral ablation on a circadian pituitary adrenocorticotropic rhythm in $\mathrm{C}$ mice. Endocrinology 1965; 76: 895-901.

[166] Scheving LE, Tsai TS, Powell EW, Pasley JN, Halberg F, Dunn J. Bilateral lesions of suprachiasmatic nuclei affect circadian rhythms in $\left[{ }^{3} \mathrm{H}\right]$-thymidine incorporation into deoxyribonucleic acid in mouse intestinal tract, mitotic index of corneal epithelium, and serum corticosterone. Anat Rec 1983; 205: 239-49.

[167] Cornelissen G, Halberg F. Introduction to Chronobiology. Medtronic Chronobiology Seminar \#7, April 1994; p. 52. (Library of Congress Catalog Card \#94-060580; Avaiable at: http://www. msi.umn.edu/ halberg/)

[168] Yamamoto T, Nakahata Y, Soma H, Akashi M, Mamine T, Takumi T. Transcriptional oscillation of canonical clock genes in mouse peripheral tissues. BMC Molecular Biology 2004; 5: 18.

[169] Takumi T, Yamamoto T, Cornelissen G, Hoogerwerf WA, Halberg F. Peripheral murine clock gene variation and extent of synchronization. Proceedings, International Conference on the Frontiers of Biomedical Science: Chronobiology; 2006 Sept 24-26; Chengdu, China 2006; pp. 228-31.

[170] Sothern RB, Cornelissen G, Yamamoto T, Takumi T, Halberg F. Time microscopy of circadian expression of cardiac clock gene mRNA transcription: chronodiagnostic and chrono-therapeutic implications. La Clinica Terapeutica 2009; 160(2): e25-34.

[171] Sothern RB, Yamamoto T, Cornelissen G, Takumi T, Halberg F. Central and peripheral circadian clock genes, their statistical analysis for rhythms, and relationship to health and disease. Scripta medica (Brno) 2009; 82: 133-63.

[172] Hoogerwerf WA, Shahinian VB, Cornelissen G, et al. Rhythmic changes in colonic motility are regulated by period genes. Am J Physiol Gastrointest Liver Physiol 2010; 298: G143-50.

[173] Hoogerwerf WA, Hellmich HL, Cornelissen G, et al. Clock gene expression in the murine gastrointestinal tract: endogenous rhythmicity and effects of a feeding regimen. Gastroenterology 2007; 133: 1250-60.

[174] Bostwick J, Nguyen D, Cornelissen G, Halberg F, Hoogerwerf WA. Effects of acute and chronic STZ-induced diabetes on clock gene expression and feeding in the gastrointestinal tract. Mol Cell Biochem 2010; 338(1-2): 203-13.

[175] Arble DM, Bass J, Laposky AD, Vitaterna MH, Turek FW. Circadian timing of food intake contributes to weight gain. Obesity 2009; 17: 2100-2.

[176] Turek FW, Joshu C, Kohsaka A, et al. Obesity and metabolic syndrome in circadian Clock mutant mice. Science 2005; 308: 1043-5.

[177] Kohsaka A, Laposky AD, Ramsey KM, et al. High-fat diet disrupts behavioral and molecular circadian rhythms in mice. Cell Metab 2007; 6: 414-21.

[178] Ma Y, Bertone ER, Stanek EJ III, et al. Association between eating patterns and obesity in a free-living US adult population. Am J Epidemiol 2003; 158: 85-92.

[179] Colles SL, Dixon JB, O'Brien PE. Night eating syndrome and nocturnal snacking: association with obesity, binge eating and psychological distress. Int J Obes (London) 2007; 31: 1722-30.

[180] O'Reardon JP, Ringel BL, Dinges DF, et al. Circadian eating and sleeping patterns in the night eating syndrome. Obes Res 2004; 12: 1789-96.

[181] Halberg F. Biological as well as physical parameters relate to radiology. Guest Lecture, Proc. 30th Ann. Cong. Rad., January 1977, Post-Graduate Institute of Medical Education and Research, Chandigarh, India, p. 8.

[182] Halberg F, Halberg J, Halberg E, Halberg F. Chronobiology, radiobiology and steps toward the timing of cancer radiotherapy. 
In: Goldson AL, Volume Ed. Cancer growth and progression. vol. 9, ch. 19, Kaiser H, Series Ed. Dordrecht: Kluwer Academic Publ. 1989; pp. 227-53.

[183] Halberg F, Prem K, Halberg F, Norman C, Cornelissen G. Cancer Chronomics I: Origins of timed cancer treatment: early marker rhythm-guided individualized chronochemotherapy. J Exp Ther Oncol 2006; 6: 55-61.

[184] Halberg F, Cornelissen G, Grambsch P, et al. Personalized chronobiologic cybercare; other chronomics' progress by transdisciplinary cycles' congruences: Season's Appreciations 2009. J Appl Biomed 2011; 9: 1-34.
[185] Cornelissen G, Grambsch P, Sothern RB, Katinas G, Otsuka K, Halberg F. Congruent biospheric and solar-terrestrial cycles. J Appl Biomed 2011; 9: 63-102.

[186] Halberg F. Some correlations between chemical structure and maximal eosinopenia in adrenalectomized and hypophysectomized mice. J Pharmacol exp Ther 1952; 106: 135-49.

[187] Halberg F. Some physiological and clinical aspects of 24-hour periodicity. Lancet (Minneapolis) 1953; 73: 20-32.

[188] Smolensky M, Halberg F, Sargent F II. Chronobiology of the life sequence. In: Itoh S, Ogata K, Yoshimura H, Eds. Advances in Climatic Physiology. Tokyo: Igaku Shoin Ltd 1972; pp. 281-318.

(C) Germaine Cornelissen; Licensee Bentham Open.

This is an open access article licensed under the terms of the Creative Commons Attribution Non-Commercial License (http://creativecommons. org/licenses/ by-nc/3. 0/) which permits unrestricted, non-commercial use, distribution and reproduction in any medium, provided the work is properly cited. 